\title{
Habitat utilization and movement patterns of subadult largemouth bass (Micropterus salmoides) in the Ohio River
}

\author{
Elizabeth Marie Hoffman \\ West Virginia University
}

Follow this and additional works at: https://researchrepository.wvu.edu/etd

\section{Recommended Citation}

Hoffman, Elizabeth Marie, "Habitat utilization and movement patterns of subadult largemouth bass (Micropterus salmoides) in the Ohio River" (2001). Graduate Theses, Dissertations, and Problem Reports. 1304.

https://researchrepository.wvu.edu/etd/1304

This Thesis is protected by copyright and/or related rights. It has been brought to you by the The Research Repository @ WVU with permission from the rights-holder(s). You are free to use this Thesis in any way that is permitted by the copyright and related rights legislation that applies to your use. For other uses you must obtain permission from the rights-holder(s) directly, unless additional rights are indicated by a Creative Commons license in the record and/ or on the work itself. This Thesis has been accepted for inclusion in WVU Graduate Theses, Dissertations, and Problem Reports collection by an authorized administrator of The Research Repository @ WVU. For more information, please contact researchrepository@mail.wvu.edu. 


\title{
Habitat Utilization and Movement Patterns of Subadult Largemouth Bass (Micropterus salmoides) in the Ohio River
}

By

\author{
Elizabeth Marie Hoffman
}

\author{
A Thesis submitted to the \\ College of Agriculture, Forestry, and Consumer Sciences \\ at West Virginia University \\ in partial fulfillment of the requirements \\ for the degree of \\ Master of Science \\ In \\ Wildlife and Fisheries Science
}
Kyle J. Hartman, Ph.D., Chair
Patricia Mazik, Ph.D.
Scott Morrison
Todd Petty, Ph.D.

West Virginia University

Morgantown, WV

2001

Keywords: largemouth bass, Ohio River, habitat use, habitat availability, biotelemetry, habitat assessment, large river ecology

(C) Copyright 2001 Elizabeth Marie Hoffman 


\section{Abstract \\ Habitat Utilization and Movement Patterns of Subadult Largemouth Bass (Micropterus salmoides) in the Ohio River}

\section{Elizabeth Marie Hoffman}

Ohio River electrofishing surveys identified embayments as preferred macrohabitat of subadult largemouth bass. Catch rates within macrohabitats were low ranging from $0.00-2.73$ subadult bass/hour. Embayment electrofishing CPUE was higher than tributary or main channel except in spring, when tributary CPUE was highest.

Core use areas were calculated from biotelemetry data and ranged from 88$59,400 \mathrm{~m}^{2}$, representing $0.02-89.00 \%$ of available study location macrohabitat. Subadult bass movement was limited to nursery embayments or tributaries with infrequent movement to nearby main channel areas. Bass preferred a mixed microhabitat consisting of a combination of vegetation and woody debris. This mixed microhabitat was less common in main channel habitat assessments compared to tributaries and embayments.

Core use areas of Ohio River subadult bass are larger than reported in impoundment studies $\left(<11,684 \mathrm{~m}^{2}\right)$, suggesting Ohio River habitat is poorer than other systems. Management should focus on habitat restoration rather than stocking to enhance Ohio River bass fisheries. 


\section{Dedication}

To Bryan

Through it all you have given me your devotion, love, and support. You have always understood. I will never be able to thank you enough. 


\section{Acknowledgements}

I would like to thank Dr. Kyle Hartman as well as the rest of my committee members Dr. Patricia Mazik, Dr. Todd Petty, and Scott Morrison for their assistance and guidance throughout this research project. I would also like to thank the West Virginia Division of Natural Resources for providing the funds that supported this research, as well as providing us with a place to stay while conducting our field sampling. A special thank you goes to Gary Batten of the WVDNR for providing endless assistance with repairs and maintenance, as well as important information, such as where to get a boat with a hole in it fixed. Mr. Grafton provided me with the necessary texts to enable identification of the Ohio River aquatic flora. My colleagues Eric Janney and Jason Freund, provided assistance in the field. The statistical analysis would never have been finished without the expert assistance of Mike Kaller and John Sweka. I would also like to thank Dorothy Tinkler for her help with the Corpscon software as well as the mapping in Arcview. Last but not least, I would like to thank my parents for their love and support while I continued my education. This research was conducted under the provisions of the West Virginia University Animal Care and Use Committee protocol \#9806-04. 


\section{TABLE OF CONTENTS}

$\begin{array}{lr}\text { Abstract } & \text { ii } \\ \text { Dedication } & \text { iii } \\ \text { Acknowledgements } & \text { iv } \\ \text { List of Tables } & \text { vi } \\ \text { List of Figures } & \text { vii }\end{array}$

Chapter One: Ecology of large river systems with an emphasis on largemouth bass and their management

- Large river systems

- Black bass ecology and management

- Literature cited
1

4

13

Chapter Two: Habitat utilization and movement patterns of subadult largemouth bass in the Ohio River

- Abstract

- Methods

- Results

- Discussion

- Literature Cited

Appendix

Curriculum Vitae 


\section{List of Tables}

Table 1. Length and weight information from all anchor

and radio transmitter tagged subadult largemouth bass.

Table 2. Summary of electrofishing effort and catch results of subadult largemouth bass.

Table 3. Results of chi-square analysis of microhabitat categories for use in proportion to availability.

Table 4. Comparison of microhabitat utilization from telemetry locations with habitat availability from transect data in sites within the Willow Island and Belleville pools of the Ohio River.

Table 5. Water quality results for all study locations sampled for subadult largemouth bass in the Willow Island and Belleville pools of the Ohio River.

Table 6. Comparison of means for aquatic vegetation amounts using Kruskal-Wallis and log transformed ANOVA.

Table 7. Dominant plant species in all macrohabitats sampled as part of subadult largemouth bass habitat use studies in the Ohio River 1998-2000.

Table 8. Comparison of Kruskal-Wallis and log transformed ANOVA results for habitat assessment across study locations.

Table 9. Comparison of log transformed ANOVA and KruskalWallis results for habitat assessment data by macrohabitat type.

Table 10. Comparison of core use area sizes from biotelemetry locations for subadult largemouth bass in the Ohio River.

Table 11. Results of ANOVA and Kruskal-Wallis statistical analysis for core use areas of subadult largemouth bass across fish length, weight, capture season and year, and available area of habitat. 


\section{List of Figures}

Figure 1. Map of the Ohio River showing placement 68 of lock and dams and basin drainage.

Figure 2. Location of Ohio River study areas. 69

Figure 3. Transect design for habitat availability determination. 70

Figure 4. Seasonal subadult largemouth bass CPUE 71

(bass per hour) by macrohabitat type in boat electrofishing surveys.

Figure 5. Radio telemetry locations and core use area 72

within the French Run embayment for the subadult

largemouth bass tagged with the frequency $48.331 \mathrm{mHz}$.

Figure 6. Radio telemetry locations and core use area within

the Indian Run tributary for the subadult largemouth bass tagged with the frequency $48.331 \mathrm{mHz}$.

Figure 7. Radio telemetry locations and core use areas within

the Lee Creek tributary for the subadult largemouth bass tagged with the frequencies 48.735 and $48.754 \mathrm{mHz}$.

Figure 8. Radio telemetry locations and core use areas within with the frequencies 48.814 and $48.834 \mathrm{mHz}$. 


\section{Chapter One:}

\section{Ecology of large river systems with an emphasis on largemouth bass and their management}

\section{Large River Systems}

Most of our large river systems in the United States have been severely altered (Scheidegger and Bain 1995). The construction of lock and dam systems for navigation, flood control, and hydroelectricity; the separation of the main channel from its floodplain for agricultural purposes; and poor land-use practices have all had a negative impact on the overall health and productivity of our large river systems (Bayley 1995, Scheidegger and Bain 1995). The interstate, and consequently interjurisdictional nature of large rivers, result in some unique problems for fisheries managers (Montgomery 1991). Effective management strategies must take the complexity of large river systems into account, requiring cooperation and coordination among various agencies. The large river ecosystems of the U.S. support a great diversity of fish species and conservation of this diversity is an important challenge (Scheidegger and Bain 1995). Compounding the numerous problems faced by large river ecosystems is the introduction of non-native species, intentional or otherwise, which can cause great damage to the native fauna. Alterations in stream flow are widespread anthropogenic disturbances (Bain et al. 1988) which can have detrimental effects on sensitive littoral areas, which contain most of the fish biomass and species, and serve as nursery areas (Kinsolving and Bain 1993, Scheidegger and Bain 1995). However, the most immediate threat to river productivity may be due to increasing sedimentation rates from poor floodplain land-use and river modifications, resulting in habitat degradation 
(Scheidegger and Bain 1995). The high rate of sedimentation in the backwater areas of the Mississippi River have lead to decreased water depth, increased growth of nuisance vegetation, and seasonally anoxic conditions (Brietenbach and Peterson 1980, Gent et al. 1995). The estimated life expectancy of some Mississippi backwater areas is no more than 50 years, unless measures are taken to stop the high sedimentation rates (Gent et al. 1995).

The Ohio River begins in Pittsburgh, Pennsylvania at the confluence of the Allegheny and Monongahela rivers, and runs 981 miles to join the Mississippi River in Cairo, Illinois (Figure 1) (Robinson 1983). A 1983 survey identified 141 fish species present in the Ohio River, 127 of which are native and 14 introduced (Pearson and Krumholz 1984). Alterations of the Ohio began as early as 1824 with the passage of the Rivers and Harbors Act and the General Survey Act, calling for planning of transportation improvements in US waterways and snag removal in the Mississippi and Ohio rivers (Robinson 1983). Channelization of the river began in 1869 and the current lock and dam system, in operation since the late 1920's, has divided the Ohio into a series of pools with heavily sedimented tributaries (Pearce 1989). The installation of the current high-lift dams also created a new macrohabitat within the river, creating embayments at the mouth of inundated creeks. There are presently 20 lock and dam structures in place along the Ohio River, which maintain a 9-foot channel depth for navigation purposes (Pearson and Krumholz 1984). In vulnerable sections of the river, riprap has been installed to limit erosion and for use as cover by fish however, this may not be preferred habitat for species such as largemouth bass (Micropterus salmoides), and may further limit the creation of natural cover. 
Other Navigation-related alterations of the Ohio River may further limit fish production. Dredging activities to maintain navigation channels for shipping may have a detrimental effect on fish habitat by increasing turbidity. Water level fluctuations from lock and dams during spawning season can result in nest and egg destruction from smothering or desiccation, and reduced productivity due to nest desertion or failure of females to spawn (Brietenbach and Peterson 1980, Kohler et al. 1993). However, high water levels during the spawning and growing seasons have been shown to create additional cover for fish in flooded bank vegetation, and can result in increased age-0 bass abundance (Kohler et al. 1993). This could be especially important in systems like the Ohio River that generally have little aquatic vegetation.

Alterations of the main channel and poor land-use practices have resulted in decreased amounts of backwater habitat. In other large river ecosystems, these backwater habitats have been shown to be extremely important for largemouth bass, especially during the overwintering period (Brietenbach and Peterson 1980, Carlson 1992, Raibley et al. 1997). In both the Hudson and Mississippi Rivers large numbers of adult largemouth bass have been found to overwinter in a few select areas, bypassing other backwaters (Brietenbach and Peterson 1980, Carlson 1992). Jackson and Starret (1959) associated sedimentation of backwater areas of the Illinois River with largemouth bass population declines. Pearson and Krumholz (1984) investigated fish distributions throughout the entire Ohio River, and discovered basses may be most abundant in sections of the river where there is the highest amount of embayment habitat present. Little is currently known about the importance of embayment or other macrohabitat types to the largemouth bass populations within the Ohio River at various life stages. 


\section{Black Bass Ecology and Management}

Black bass (Micropterus spp.) are widely distributed across North America and are an extremely popular sportfish in the U.S. (Anderson 1984, Carmichael et al. 1984, Fullerton et al. 2000, McCauley and Kilgour 1990, Post et al. 1998) and all signs suggest their popularity will continue to grow. Largemouth bass are found along the entire length of the Ohio River. Data from lock rotenone surveys from 1957-1980 show an increase in largemouth bass biomass from 0.08 to $0.99 \mathrm{~kg} / \mathrm{ha}$ (Pearson and Krumholz 1984). Fisheries managers currently utilize a variety of policies to manage or enhance black bass stocks, including closed spawning season, catch and release, length and harvest regulations as well as water level manipulations (Kohler et al. 1993, Philipp et al. 1997).

In the state of West Virginia a 1991 survey found bass fishing accounted for $53 \%$ of total fishing effort. In 1992 anglers spent 109.2 million dollars on fishing activities, which means bass anglers contributed approximately 57.8 million dollars to the state's economy that year, and likely have spent as much or more every year since that time (U.S. Department of the Interior 1993).

The popularity of the black bass, particularly largemouth bass, has resulted in a great deal of research on bass and their general ecology (Post et al. 1998). Largemouth inhabit lakes, ponds, reservoirs, rivers, and even coastal areas with tidal influences from the southern U.S. into Canada and are intensively cultured (Carmichael et al. 1984, Meador and Kelso 1989). In many pond and lake habitats, they are the dominant predator and usually account for a large percentage of total fish biomass 
(Anderson 1984). There are two known sub-species of largemouth bass, the Northern (M. salmoides salmoides), and Florida (M. salmoides floridanus) (Fullerton et al. 2000).

While largemouth bass have been well studied in lake and reservoir systems, there are many unanswered questions regarding their ecology within large river ecosystems. A great deal of the research to date has focused on adult fish in reservoir settings (Scheidegger and Bain 1995). As a result there are large gaps in our knowledge of the critical age-0, and juvenile life stages (Irwin et al. 1997, Kohler et al. 1993, Scheidegger and Bain 1995, Woodward 1996). Our understandings of seasonal movements and habitat preferences in the critical subadult stages are limited, particularly in riverine systems. More research on habitat use and how it relates to bass abundance and distribution is needed and will benefit the management of complex systems, such as large rivers (Irwin et al. 1997). Within the Mississippi River basin the lack of information on habitat requirements for many fish species, including the largemouth bass, is a serious concern (Montgomery 1991). Without this baseline information on basic ecology, it is extremely difficult to form and implement effective fishery management plans.

Habitat use is an important component of largemouth bass ecology, and many studies have focused on this area. However, much of the work has dealt only with adults and as a result our knowledge of habitat use and how it influences juvenile populations is limited (Irwin et al. 1997). Research on largemouth habitat use has shown them to be specialized feeders at low and intermediate levels of vegetative cover, becoming generalists at high structure levels, possibly in an attempt to overcome reduced prey encounter rates (Anderson 1984). Kinsolving and Bain (1993) 
categorized largemouth bass as macrohabitat generalists, which attests to their wide distribution. There is also evidence to suggest they are capable of switching habitats with changing forage availability and that a risk versus benefit balance is reached with habitat selection (Werner et al. 1983).

For many fish species, increased habitat complexity leads to increased recruitment, growth, and survival (Caselle and Warner 1996, Power 1992). In addition, Thorp (1992) identified a positive relationship between habitat heterogeneity and fish abundance and productivity in the Ohio River. Irwin et al. (1997) found age-0 bass had consistently patchy distributions and proposed the arrangement and size of nursery habitat patches may be important for bass recruitment. This may be especially true for strong year classes, when habitat may be limiting. Scheidegger and Bain (1995) identified gently sloping shorelines, woody cover, low water velocity, and aquatic vegetation as important components of nursery habitat for centrarchids. Steep shoreline slopes and gravel sized substrates were associated with age-0 largemouth bass in an unvegetated reservoir (Irwin et al. 1997).

Advancements in technology, such as biotelemetry equipment, have aided scientists in the investigation of movement patterns in many species of fish. However, similar to habitat preferences, much of the work on largemouth bass has focused only on the adults, so we do not have a complete understanding of the differences between adult and juvenile bass movements (Woodward 1996). Recent improvements in telemetry technology, particularly increased battery life and reduced tag size, have increased our ability to study subadult fish. Adult largemouth bass have exhibited use of home areas (approximately 61-122 meters in diameter) during the spring and 
summer months, returning to areas year after year, then moving offshore into deeper waters for overwintering (Hasler and Wisby 1958, Lewis and Flickinger 1967). Diana (1983) found water temperature may be the controlling factor in summer movements by adults, with bass staying in nearshore areas when temperatures were less than $25^{\circ} \mathrm{C}$ and moving offshore when nearshore temperatures exceeded $25^{\circ} \mathrm{C}$. During winter, bass in riverine habitats are inactive and found to collect in backwater areas, where water velocity is lower and water temperature higher than the main channel (Carlson 1992, Pitlo 1992, Raibley et al. 1997). The inactivity results from decreased metabolism due to low water temperatures, and bass have been found to enter a hibernation-like state when water temperature drops below $10^{\circ} \mathrm{C}$, which reduces energy requirements (Fullerton et al. 2000, Johnson and Charlton 1960). A radio telemetry study in a North Carolina reservoir by Woodward (1996) found juvenile largemouth exhibited similar patterns of movement to adults, having well defined home ranges and infrequent movements outside the home area. In both adult and subadult bass populations the majority of fish appear fairly sedentary, with a small percentage being more active and mobile (Woodward 1996). Research conducted by Copeland and Noble (1994) suggested most subadult bass move less than 60 meters in the first two years of life. If this is the case in systems such as the Ohio River, fishery managers may be able to focus their efforts on portions of the river identified as nursery areas and have a greater impact on the overall largemouth population. A localized approach utilizing habitat restoration techniques may maximize the benefits to bass populations (Copeland 1992). Largemouth initiate spawning activity in spring when water temperatures reach $15-20{ }^{\circ} \mathrm{C}$ (Johnson and Charlton 1960, Philipp et al. 1997). In temperate regions the 
spawning season can last from two to ten weeks (Phillips et al. 1995). Sheltered littoral zones are the preferred spawning location (Copeland 1992). Males construct a nest and give parental care to the eggs and swim-up fry, remaining for four or more weeks to protect the young. Abiotic factors, such as water temperatures or levels, may affect the length of time spent guarding a nest and survival of larvae (Kohler et al. 1993, Pine et al. 2000). Survival of the young bass is greatly improved the longer the male guards the nest. The length of time spent guarding a nest is size dependent, as male bass limit feeding while on a nest, and thus depend on energy reserves. Since females spawn preferentially with the largest males, they are the most productive, but the correlation between individual spawning and nest success and overall recruitment is not completely understood. (Philipp et al. 1997)

Similar to many other fishes, bass undergo diet shifts in early life history (Olson 1996, Phillips et al. 1995). In largemouth bass the shifts in diet are size-dependent, as they are gape-limited predators (Olson 1996). The first diet shift is from zooplankton to invertebrate prey and occurs early in the first season (Olson 1996). The second shift from invertebrate to fish prey usually occurs later in the first year of life (when age-0 bass are 40-80 mm in length), but can vary a great deal (Olson 1996, Olson et al. 1995, Phillips et al. 1995).

The timing of the switch to piscivory has major consequences for growth, recruitment, and survival (Fullerton et al. 2000, Ludsin and De Vries 1997, Olson et al. 1995). It is generally accepted that the earlier age-0 bass are able to make the switch to piscivory, the higher growth rates will be, and the greater the chance of survival, especially through the critical first overwinter period (Garvey et al. 1998, Miranda and 
Hubbard 1994, Olson 1996, Post et al. 1998). However, if age-0 bass do not have a size advantage over faster growing prey species in spring, the size disparity will continue to increase through the growing season, making a later switch to piscivory unlikely and further reducing bass growth rates, possibly delaying the diet switch to fish prey until the following year (Olson 1996). Once young bass become piscivorous, bluegill (Lepomis macrochirus) and gizzard shad (Dorosoma cepedianum) are important prey species, however prior to the diet shift, age-0 bass and bluegill may actually be competitors for invertebrate prey (Bulkley 1975, Garvey and Stein 1998, Olson 1996, Olson et al. 1995). Insect larvae and adults are dominant prey items for both young largemouth bass and bluegill, however some resource partitioning may occur between the two species. Gape limitations of young bass may limit feeding to only a portion of available invertebrate prey (Olson et al. 1995).

Fish recruitment in general is highly variable, making research in this field difficult (Miranda and Hubbard 1994, Post et al. 1998, Pine et al. 2000). Recent studies have been focusing on a multitude of factors and their interactions as controlling recruitment to the fishery (Garvey and Stein 1998, Kohler et al. 1993, Olson 1996). Factors that have been identified as controlling recruitment in bass include predation, mortality (especially over the first winter), rearing habitat availability, growth rates, forage availability and quality, intra- and inter-specific competition, hatch rates, ontogenetic niche shifts, and abiotic factors (such as water temperature, levels, and turbidity) (Garvey and Stein 1998, Garvey et al. 1998, Irwin et al. 1997, Kohler et al. 1993, Miranda and Hubbard 1994, Miranda et al. 1984, Olson 1996, Post et al. 1998). Summer predation rates of bass may regulate growth and affect recruitment by 
controlling first year survival (Post et al. 1998). Mortality over the critical first winter appears to be largely size-dependent (Post et al. 1998, Garvey and Stein 1998, Miranda and Hubbard 1994), however larger does not necessarily mean better survival, as factors affecting mortality probably vary a great deal across systems and years (Garvey et al. 1998). The availability of nursery habitat may be density-dependant and ultimately affect total recruitment (Irwin et al. 1997). Growth is another highly variable densitydependant factor in recruitment (Post et al. 1998) and is largely dependent on diet, particularly prey availability and quality (Garvey et al. 1998, Miranda and Hubbard 1994). Intra-specific competition for preferred habitat or prey items increases with an increase in bass density, and can limit recruitment into the adult population (Irwin et al. 1997, Garvey et al. 1998). Inter-specific competition with bluegill for invertebrate prey has been identified as a mechanism that may limit recruitment (Olson et al. 1995). Individual or overall spawning success as well as timing may not have a direct link to recruitment, but it does affect year-class strength, which ultimately does play a role in determining recruitment (Post et al. 1998, Garvey and Stein 1998, Miranda and Hubbard 1994).

Ontogenetic diet shifts (the ability to forage on larger and higher quality prey items) in largemouth bass are size-dependant and the timing of these shifts may play a major role in recruitment determination in some systems (Ludsin and DeVries 1997, Garvey and Stein 1998, Miranda and Hubbard 1994). Some of the effects abiotic factors may have on recruitment of largemouth bass are not completely understood, however water temperature, turbidity, and water level appear to be important during spawning season (Copeland 1992, Garvey and Stein 1998, Kohler et al. 1993, Pine et 
al. 2000). While there has been a great deal of research conducted in an attempt to understand the recruitment process in largemouth, there appear to be no easy answers (Pine et al. 2000). Most likely, it is the cumulative effect of many variables acting on subadult populations which eventually regulates year class strength, and recruitment into the fishery (Post et al. 1998). The ability to accurately predict recruitment success depends on our knowledge of growth and survival of sub-adult fish (Pine et al. 2000) and would be extremely beneficial to managers.

Since recruitment appears to be determined in the juvenile life stage (Pine et al. 2000 ), it is critical that we gain a better understanding of the requirements for sub-adult bass in order to manage this species effectively. It may be possible, and most cost effective, for fishery managers to focus their resources on specific areas (such as tributary or embayment habitat) in complex river ecosystems and positively affect the entire river population. The Ohio River is a large and complex system in which largemouth bass are an integral part of the recreational fishery. In 1997 a 23-year record low tournament bass catch rate (Janney 2001) raised concerns from the public and fishery managers alike and is believed to be due to low recruitment. Habitat quality and quantity appear to be important factors in largemouth bass recruitment (Irwin et al. 1997, Scheidegger and Bain 1995). Therefore, the objective of this research project is to determine habitat usage for subadult largemouth bass within the Ohio River. This is an economically important species to the state of West Virginia, and the popularity of the fishery appears to be on the increase. With popularity comes demand for larger numbers of quality size fish. By investigating the ecology of the age- 0 and juvenile life stages we hope to provide fishery managers with information they can use to guide 
decisions on preservation and possible rehabilitation of critical largemouth bass habitat. The specific objectives of this project are:

1) Determine the importance of various macrohabitat types (main channel, embayment, and tributary) to subadult largemouth bass.

2) Identify movement patterns within and among these macrohabitat types.

3) Quantify microhabitat present in the Ohio River and identify habitat selection by subadult bass.

4) Estimate core-use areas for subadult largemouth bass and estimate areas of available habitat in study locations. 


\section{Literature Cited}

Anderson, O. 1984. Optimal foraging by largemouth bass in structured environments. Ecology 65:851-861.

Bain, M.B., J.T. Finn and H.E. Booke. 1988. Streamflow regulation and fish community structure. Ecology 69:382-392.

Bayley, P.B. 1995. Understanding large river-floodplain ecosystems. Bioscience 45:153158.

Brietenbach, R. and G. Peterson (eds). 1980. Fish and wildlife management work group appendix, Great River Environmental Action Team II (GREAT II). U.S. Fish and Wildlife Service, Rock Island, IL.

Bulkley, R.V. 1975. Chemical and physical effects on the centrarchid basses. Page 286 in $\mathrm{H}$. Clepper (ed.), Black bass biology and management. Sport fishing institute, Washington D.C.

Carlson, M.D. 1992. Importance of wintering refugia to the largemouth bass fishery in the Hudson River Estuary. Journal of Freshwater Ecology 7(2):173-180.

Carmichael, G.J., J.R. Tomasso, B.A. Simco, and K.B. Davis. 1984. Confinement and water quality-induced stress in largemouth bass. Transactions of the American Fisheries Society 113:767-777.

Caselle, J.E., and R.R. Warner. 1996. Variability in recruitment of coral reef fishes: the importance of habitat at two spatial scales. Ecology 77:2488-2504.

Copeland, J.R. 1992. Evidence for site fidelity in young-of-year largemouth bass: implications for reservoir fisheries management. North Carolina State University. Raleigh, NC.

Copeland, J.R. and R.L. Noble. 1994. Movements by young-of-year and yearling largemouth bass and their implications for supplemental stocking. North American Journal of Fisheries Management 14:119-124.

Diana, J.S. 1983. Oxygen consumption by largemouth bass under constant and fluctuating thermal regimes. Canadian Journal of Zoology 61:1892-1895.

Fullerton, A.H., J.E. Garvey, R.A. Wright, and R.A. Stein. 2000. Overwinter growth and survival of largemouth bass: interactions among size, food, origin, and winter severity. Transactions of the American Fisheries Society 129:1-12. 
Garvey, J.E., and R.A. Stein. 1998. Linking bluegill and gizzard shad prey assemblages to growth of age-0 largemouth bass in reservoirs. Transactions of the American Fisheries Society 127:70-83.

Garvey, J.E., R.A. Wright, and R.A. Stein. 1998. Overwinter growth and survival of age0 largemouth bass (Micropterus salmoides): revisiting the role of body size. Canadian Journal of Fisheries and Aquatic Sciences 55:2414-2424.

Gent, R., J. Pitlo, and T. Boland. 1995. Largemouth bass response to habitat and water quality rehabilitation in a backwater of the upper Mississippi River. North American Journal of Fisheries Management 15:784-793.

Hasler, A.D. and W.J. Wisby. 1958. The return of displaced largemouth bass and green sunfish to a "home" area. Ecology 39:289-293.

Irwin, E.R., R.L. Noble, and J.R. Jackson. 1997. Distribution of age-0 largemouth bass in relation to shoreline landscape features. North American Journal of Fisheries Management 17:882-893.

Jackson, H.O. and W.C. Starret. 1959. Turbidity and sedimentation at Lake Chautauqua, III. Journal of Wildlife Management 23:157-168.

Janney, E.C. 2001. Evaluation of a fall stocking of adult and intermediate largemouth bass (Micropterus salmoides) into two Ohio River embayments. West Virginia University, Morgantown, WV. Master's Thesis.

Johnson, M.G., and W.H. Charlton. 1960. Some effects of temperature on the metabolism and activity of the largemouth bass, Micropterus salmoides Lacepede. The Progressive Fish-Culturist October 1960:155-163.

Kinsolving, A. D. and M.B. Bain. 1993. Fish assemblage recovery along a riverine disturbance gradient. Ecological Applications 3:531-544.

Kohler, C.C, R.J. Sheehan, and J.J. Sweatman. 1993. Largemouth bass hatching success and first-winter survival in two Illinois reservoirs. North American Journal of Fisheries Management 13:125-133.

Lewis, W.M. and S. Flickinger. 1967. Home range tendency of the largemouth bass (Micropterus salmoides). Ecology 48:1020-1023.

Ludsin, S.A. and D.R. DeVries. 1997. First-year recruitment of largemouth bass: the inter-dependency of early life stages. Ecological Applications 7:1024-1038.

McCauley, R.W. and D.M. Kilgour. 1990. Effect of air temperature on growth of largemouth bass in North America. Transactions of the American Fisheries Society 119:276-281. 
Meador,M.R. and W.E. Kelso. 1989. Behavior and movements of largemouth bass in response to salinity. Transactions of the American Fisheries Society 118:409-415.

Miranda, L.E. and W.D. Hubbard. 1994. Length-dependant winter survival and lipid composition of age-0 largemouth bass in Bay Springs reservoir, Mississippi.

Transactions of the American Fisheries Society 123:80-87.

Miranda, L.E., W.L. Shelton, and T.D. Bryce. 1984. Effects of water level manipulation on abundance, mortality, and growth of young-of-year largemouth bass in West Point reservoir, Alabama-Georgia. North American Journal of Fisheries Management 4:314320.

Montgomery, R. 1991. Restoring large river fishery resources: the Mississippi interstate cooperative resource agreement. Fisheries 16:44-47.

Olson, M.H. 1996. Ontogenetic niche shifts in largemouth bass: variability and consequences for first-year growth. Ecology 77:179-190.

Olson, M.H., G.G. Mittelbach, and C.W. Osenberg. 1995. Competition between predator and prey: resource-based mechanisms and implications for stage-structured dynamics. Ecology 76:1758-1771.

Pearce, J.E. 1989. The Ohio River. University press of Kentucky, Lexington, KY.

Pearson, W.D. and L.A. Krumholz. 1984. Distribution and status of Ohio River fishes. University of Louisville. Louisville, Kentucky.

Philipp, D.P., C.A. Toline, M.F. Kubacki, D.B. F. Philipp, F.J.S. Phelan. 1997. The impact of catch-and-release angling on the reproductive success of smallmouth bass and largemouth bass. North American Jounral of Fisheries Management 17:557-567.

Phillips, J.M., J.R. Jackson, and R.L. Noble. 1995. Hatching date influence on agespecific diet and growth of age-0 largemouth bass. Transactions of the American Fisheries Society 124:370-379.

Pine, W.E., S.A. Ludsin, and D.R. DeVries. 2000. First-summer survival of largemouth bass cohorts: is early spawning really best? Transactions of the American Fisheries Society 129:504-513.

Pitlo, J. 1992. An evaluation of largemouth bass populations in the upper Mississippi River. lowa Department of Natural Resources, Federal Aid to Fish Restoration, Project F-109-R, Final Report, Des Moines.

Post, D.M., J.F. Kitchell, and J.R. Hodgson. 1998. Interactions among adult demography, spawning date, growth rate, predation, overwinter mortality, and the 
recruitment of largemouth bass in a northern lake. Canadian Journal of Fisheries and Aquatic Sciences 55:2588-2600.

Power, M.E. 1992. Habitat heterogeneity and the functional significance of fish in river food webs. Ecology 73:1675-1688.

Raibley, P.T., K.S. Irons, T.M. O'Hara, K.D. Blodgett, and R.E. Sparks. 1997. Winter habitats used by largemouth bass in the Illinois River, a large river-floodplain ecosystem. North American Journal of Fisheries Management 17:401-412.

Robinson, M.C. 1983. History of navigation in the Ohio River basin. National waterway study, U.S, Army Engineer Water Resources Support Center, Institute for water resources.

Scheidegger, K.J. and M.B. Bain. 1995. Larval fish distribution and microhabitat use in free-flowing and regulated rivers. Copeia no1:125-35.

Thorp, J.H. 1992. Linkage between islands and benthos in the Ohio River, with implications for riverine management. Canadian Journal of Fisheries and Aquatic Sciences 49:1873-1882.

US Department of the Interior, Fish and Wildlife Service, U.S. Department of Commerce, Bureau of the Census. 1993. 1991 National survey of fishing, hunting, and wildlife associated recreation in West Virginia. U.S. Government Printing Office, Washington, DC.

Werner, E.E., J.F. Gilliam, D.J. Hall, and G.G. Mittelbach. 1983. An experimental test of the effects of predation risk on habitat use in fish. Ecology 64:1540-1548.

Woodward, K.O. 1996. Reservoir movements of sub-adult largemouth bass (Micropterus salmoides). North Carolina State University. Raleigh, NC. Master's Thesis. 


\section{Chapter Two:}

\section{Habitat utilization and movement patterns of subadult largemouth bass in the Ohio River}

\section{Abstract}

In this study we identify critical habitat for subadult largemouth bass at the macro and microhabitat scale. Electrofishing and biotelemetry results identified embayments as preferred macrohabitat. Preference was also established for mixed woody debris and aquatic vegetation microhabitat. Limited availability of mixed microhabitat may explain the subadult bass usage patterns observed and may be limiting largemouth bass recruitment in the Ohio River. Core use areas were calculated for subadult bass using the minimum convex polygon method. Core use areas varied greatly between individuals, ranging from $88 \mathrm{~m}^{2}$ to $59,400 \mathrm{~m}^{2}$. There were significant differences in core use areas between seasons $(P=0.0208)$ with summer use areas being the largest and spring the smallest. Subadult bass utilized between $0.02 \%$ and $89.00 \%$ of the available area in study locations. Movement patterns suggest "home-body" and "roamer" individuals, although most bass limited movements to the nursery embayment or tributary. The use areas observed in the Ohio River are larger than previous reservoir studies have suggested (generally no greater than $11,684 \mathrm{~m}^{2}$ ). A pattern of larger use areas suggests Ohio River habitat quality may be poorer than other systems. Larger core use areas may also suggest other deficiencies within the Ohio River system, such as low forage quality and/or quantity. Subadult largemouth bass in the Ohio River may need to travel further than bass in other systems to find the resources they need. 


\section{Introduction}

Black bass (Micropterus spp.) are widely distributed across North America and are extremely popular sportfishes in the United States (Anderson 1984, Carmichael et al. 1984, Fullerton et al. 2000, McCauley and Kilgour 1990, Post et al. 1998). Within the section of the Ohio River that borders West Virginia and Ohio, bass tournaments are increasing in popularity and number. In a 1992-1993 survey, largemouth bass (Micropterus salmoides) were the most sought-after fish among recreational anglers along the Ohio- West Virginia border (Schell et al. 1996). A 1991 survey found bass fishing accounted for $53 \%$ of total fishing effort in West Virginia. In 1992 bass anglers contributed approximately 57.8 million dollars to the state's economy, and likely have spent at least as much every year since that year (U.S. Department of the Interior 1993).

Largemouth bass can be found along the entire length of the Ohio River. However, a 1984 report suggested adult abundance was highest in the middle third of the river, where embayment habitats are most prevalent (Pearson and Krumholz 1984). No studies have been conducted in the Ohio River to identify habitat usage or preference and possible effects on the population as a whole. The relatively recent creation of embayment habitats is the direct result of inundation of creek mouths after the completion of the current high lift lock and dam system (Pearson and Krumholz 1984). Data from lock rotenone surveys from $1957-1980$ show an overall increase in largemouth bass biomass from 0.08 to $0.99 \mathrm{~kg} / \mathrm{ha}$ since installation of these dams (Pearson and Krumholz 1984). 
While largemouth bass have been studied in lake, impoundment, and reservoir systems, there are many unanswered questions regarding their ecology within large river ecosystems. A great deal of the research to date has focused on adult fish in reservoir settings (Scheidegger and Bain 1995). As a result there are large gaps in our knowledge of the critical age-0 and juvenile life stages (Irwin et al. 1997, Kohler et al. 1993, Scheidegger and Bain 1995, Woodward 1996). Our understandings of seasonal movements and habitat preferences in the critical subadult stages are limited, particularly in riverine systems. More research on habitat use and how it relates to bass abundance and distribution is needed and will benefit the management of complex areas, such as large rivers systems (Irwin et al. 1997). Within the Mississippi River basin the lack of information on habitat requirements for many fish species, including the largemouth bass, is a serious concern (Montgomery 1991). Without this baseline information on basic ecology, it is extremely difficult to form and implement effective fishery management plans.

In other large river ecosystems, backwater habitats have been shown to be extremely important for largemouth bass, especially during the overwintering period (Brietenbach and Peterson 1980, Carlson 1992, Raibley et al. 1997). In both the Hudson and Mississippi Rivers large numbers of adult bass have been found to overwinter in a few select backwater areas, bypassing other off-channel habitats in order to reach these preferred locations (Brietenbach and Peterson 1980, Carlson 1992). Backwater areas in the Mississippi River are being altered by high rates of sedimentation that have lead to decreased water depths, increased growth of nuisance 
vegetation, and seasonally anoxic conditions (Brietenbach and Peterson 1980, Gent et al. 1995).

The large river ecosystems of the U.S. currently face many threats to their overall health, productivity, and species diversity (Bayley 1995, Montgomery 1991, Scheidegger and Bain 1995). Widespread anthropogenic disturbances have resulted in alterations in stream flow (Bain et al. 1988) which can have detrimental effects on sensitive littoral areas, which contain most of the fish biomass and species, and serve as nursery areas (Kinsolving and Bain 1993, Scheidegger and Bain 1995). However, as in the Mississippi River, the most immediate threat may be habitat degradation due to increasing backwater sedimentation rates from poor floodplain land-use and river modifications (Pearson and Krumholz 1984, Scheidegger and Bain 1995).

The current lock and dam system, in operation since the late 1920's, has divided the Ohio River into a series of similar width pools with heavily sedimented tributaries (Pearce 1989). The sedimentation of tributaries and embayments could be especially detrimental to nest building species such as largemouth bass, which utilize these areas as spawning habitats (Pearson and Krumholz 1984). In vulnerable sections of the main channel, riprap has been installed to limit erosion and for use as cover by fish, however this may not be preferred habitat for largemouth bass, and may further limit the creation of natural cover. Other navigation-related alterations of the Ohio River may also limit fish production. Dredging activities to maintain the minimum 2.7 meter depth of navigation channels for shipping may negatively affect fish habitat by increasing turbidity and altering sediment composition. Further, water level fluctuations from lock and dams during spawning season can result in nest and egg destruction from 
smothering or desiccation, and reduced productivity due to nest desertion or failure of females to spawn (Brietenbach and Peterson 1980, Kohler et al. 1993). However, stable high water levels during the spawning and growing seasons have been shown to create additional cover for fish in flooded bank vegetation, and can result in increased age-0 bass abundance (Kohler et al. 1993). This could be especially important in systems like the Ohio River that generally have limited growth of aquatic vegetation.

For many fish species, increasing habitat complexity leads to increasing recruitment, growth, and survival (Caselle and Warner 1996, Power 1992). In addition, Thorp (1992) identified a positive relationship between habitat heterogeneity and fish abundance and productivity in the Ohio River. Irwin et al. (1997) found age-0 bass had consistently patchy distributions and proposed the arrangement and size of nursery habitat patches may be important for bass recruitment. This may be especially true for strong year classes, when habitat may be limiting. Scheidegger and Bain (1995) identified gently sloping shorelines, woody cover, low water velocity, and aquatic vegetation as important components of nursery habitat for centrarchids. Conversely, Irwin et al. (1997) found steep shoreline slopes and gravel-sized substrates were associated with age-0 largemouth bass in an unvegetated reservoir. Clearly there are significant gaps in our understanding of young largemouth bass habitat requirements, particularly in large impounded waterways, which suggests such studies are needed in rivers like the Ohio River.

Similar to habitat utilization studies, much of the work on largemouth bass movement patterns has focused only on the adults, thus we do not have a complete understanding of the differences between adult and juvenile bass movements 
(Woodward 1996). Recent improvements in telemetry technology, particularly increased battery life and reduced tag size, have increased our ability to study subadult fish. Adult largemouth bass have exhibited use of home areas (approximately 61-122 meters in diameter) during the spring and summer months, returning to areas year after year, then moving offshore into deeper waters for overwintering (Hasler and Wisby 1958, Lewis and Flickinger 1967). During winter, bass in riverine habitats are inactive and found to collect in backwater areas, where water velocity is lower and water temperature higher than the main channel (Carlson 1992, Pitlo 1992, Raibley et al. 1997). Diana (1983) found water temperature may be the controlling factor in summer movements by adults, with bass staying in nearshore areas when temperatures were less than $25^{\circ} \mathrm{C}$ and moving offshore when nearshore temperatures exceeded $25^{\circ} \mathrm{C}$.

Studies of sub-adult largemouth bass movement patterns have previously been limited to reservoir settings. Woodward (1996) found juvenile largemouth exhibited similar patterns of movement to adults, having well defined home ranges and infrequent movements outside the home area. Research conducted by Copeland and Noble (1994) suggested most subadult bass move less than 60 meters in the first two years of life. In both adult and subadult bass populations the majority of fish appear fairly sedentary, with a small percentage being more active and mobile (Woodward 1996). If this is the case in large river systems such as the Ohio River, fishery biologists may be able to focus their management efforts on portions of the river identified as nursery areas and have a greater impact on the overall largemouth population. A localized approach that includes habitat restoration techniques may maximize the benefits to largemouth bass populations (Copeland 1992). 
A great deal of research conducted in an attempt to understand the recruitment process in largemouth bass (Garvey and Stein 1998, Garvey et al. 1998, Irwin et al. 1997, Kohler et al. 1993, Miranda and Hubbard 1994, Miranda et al. 1984, Olson 1996, Pine et al. 2000, Post et al. 1998). However, we still do not have a complete understanding of all the factors that interact to control recruitment. Most likely, the cumulative effect of many variables acting on subadult populations eventually regulates year class strength, and recruitment into the fishery (Post et al. 1998). The ability to accurately predict recruitment success would be extremely beneficial to managers, and depends on our knowledge of growth and survival of sub-adult fish (Pine et al. 2000). Since recruitment appears to be determined in the juvenile life stage (Pine et al. 2000), it is critical that we gain a better understanding of the habitat and living requirements for sub-adult bass in order to manage this species effectively.

The Ohio River is a large and complex system in which largemouth bass are an integral part of the recreational fishery. In 1997 a 23-year record low tournament bass catch rate (Janney 2001) raised concerns from the public and fishery managers alike and is believed to be due to low recruitment. Habitat quality and quantity appear to be important factors in largemouth bass recruitment (Irwin et al. 1997, Scheidegger and Bain 1995). Therefore, the objective of this study is to determine habitat usage and patterns of movement for juvenile largemouth bass within the Ohio River. This is an economically important species to the state of West Virginia, and the popularity of the fishery appears to be on the increase. With popularity comes demand for larger numbers of quality size fish. By investigating the ecology of the age- 0 and juvenile life stages we hope to provide fishery managers with information they can use to guide 
decisions on preservation and possible rehabilitation of critical largemouth bass habitat in the Ohio River.

\section{Methods}

\section{Study Area}

The study areas are located along the West Virginia- Ohio border in Wood and Pleasants counties of West Virginia (Figure 2). The initial study sites were located in the lower section of the Belleville pool of the Ohio River, from river mile (RM) 195 through RM 204, in Wood County. The Belleville pool of the Ohio River is contained by the Belleville dam at RM 203.9 and the Willow Island dam at RM 161.7 on the upper end. The Belleville and Willow Island dams are high-lift dams with 6.7 and 6.1 meter lifts, respectively, from the elevation of the pool below (Pearson and Krumholz 1984). The Belleville study sites were located on both the West Virginia and Ohio sides of the river. Belleville pool sites include Lee Creek (WV), Sugarcamp Run (OH), Indian Run $(\mathrm{OH})$, Swan Run $(\mathrm{OH})$, as well as two stretches of the main channel of the Ohio River (WV). In October of 1999, French Run was added as an additional study area to improve sample size of subadult bass, after receiving information from another university research project of high electrofishing catch rates of subadult bass in that area (Eric Janney- personal communication). French Run is located in the Willow Island pool of the Ohio River, at approximately RM 158, in Pleasants County, West Virginia. 


\section{General Methods}

In order to determine which habitats subadult largemouth bass were using, we classified the river into three macrohabitat types (main channel, embayment, and tributary) and sampled each type using boat electrofishing to determine the relative abundance of bass in each type. Bass catch rates were surprisingly low in all habitat types so radio telemetry methodology was incorporated into the study in order to gather more information on habitat use. Additionally, macro and microhabitat were quantified to enable use versus availability analysis. Finally, subadult largemouth bass core use areas and greatest distance traveled were estimated to identify movement patterns and allow mapping of short-term home range.

Study locations were categorized into three macrohabitat types: main channel, embayment, and tributary. Main channel areas were composed of all aquatic habitats between the Ohio and West Virginia banks. Embayment macrohabitats are areas that were created by the inundation of small tributaries upon the completion of the current lock and dam structures. This flooding results in larger, more open areas adjacent to the main river channel that contain lentic type habitats. Tributary macrohabitats were categorized as lotic habitat: larger creeks, streams, or rivers, which feed directly into the main channel of the Ohio River.

\section{Electrofishing}

Electrofishing surveys were conducted in each macrohabitat to determine relative abundance of subadult bass in each habitat type. Preliminary electrofishing surveys were conducted in the Belleville pool on a nearly pool-wide basis in order to 
identify areas with subadult largemouth bass populations. Fish were collected with a single sphere electrode VVP-15 Coffelt $\circledast$ direct current pulse boat electrofishing unit run at a range of 2-6 amps and $80-120$ pulses/ second. Boat electrofishing has been shown to be an effective method of sampling age-0 and juvenile largemouth bass (Jackson and Noble 1995), and increasing pulse frequency has been shown to select for smaller size classes of fish (Novotny and Priegel 1974).

Electrofishing sampling locations were categorized into one of three macrohabitat types: main channel, embayment or tributary. Within larger embayments, tributaries, and the main channel starting points for surveys were randomly selected. In smaller sites, the entire shoreline was surveyed at a constant speed. Main channel macrohabitats were categorized as any area of water within the mainstem of the river (between the Ohio and West Virginia borders of the Ohio River). Electrofishing was conducted using a two-person methodology employing selective dipnetting of black bass, to maximize sampling efficiency (Twedt et al. 1992). Shoreline electrofishing surveys within the study areas were standardized at 15 minutes per survey. Electrofishing surveys were initiated with the recording of the latitude and longitude using a Garmin hand-held GPS unit, as well as the date and time at the starting point. Surveys were completed at the end of a 15-minute period, and with the recording of final position and time. Two to six shoreline electrofishing surveys were conducted monthly in each macrohabitat type from September - December 1998. Beginning in January 1999 , electrofishing surveys focused on the tributary and embayment macrohabitats after preliminary catch results yielded no subadult bass in the main channel of the Ohio River. However, we also continued to sample the main channel. 
Electrofishing surveys were conducted at least one time per month (usually 2-5 times per month) in embayment and tributary habitats from January - October in 1999 and March - June in 2000.

All largemouth bass captured during electrofishing surveys were measured to the nearest mm using total length (TL) and wet weight recorded to the nearest gram (g). For tagging purposes, we established a 305-millimeter $(\mathrm{mm})$ maximum length for subadult bass. Lengths greater than $305 \mathrm{~mm}$ were considered adult and released after length and weight measurements were recorded. After completion of the electrofishing survey and tagging of any subadult bass collected, fish were released near their point of capture and water quality and microhabitat data were recorded. Water quality was recorded during surveys using a Yellow Springs Incorporated model 3800 water quality logger (including water temperature, turbidity, depth, conductivity, salinity, and dissolved oxygen). In addition to water quality, visible microhabitat type and approximate distance to microhabitat feature were recorded for each fish capture location in each survey.

\section{Tagging}

During the first 10 months of the study uniquely numbered Floy ${ }^{\circledR}$ anchor tags were used to mark the captured subadult bass and allow for identification of recaptured individuals. The anchor tags were also imprinted with the university's name and address, as well as Dr. Hartman's office phone number to allow call-in reports from anglers catching tagged bass. The anchor tags were implanted subcutaneously through a small incision in the abdominal cavity. After poor recapture rates in subsequent electrofishing surveys, it was determined that the use of radio telemetry 
transmitters would provide more data on subadult largemouth bass habitat use and movement. Subadult largemouth bass were internally tagged with Advanced Telemetry Systems ${ }^{\circledR}$ (ATS) transmitters. Each transmitter was set with a unique radio frequency in the range of 48.090 to 48.961 megahertz $(\mathrm{MHz})$. Previous studies have indicated that the transmitter weights should be no more than $2 \%$ of a fish's total weight (Winter 1996). Based on previous bass weight data from our electrofishing surveys, three radio tag weights of $1.24,1.58$, and $1.98 \mathrm{~g}$ were selected in order to balance battery life with the $2 \%$ rule (Winter 1996). Thus, $62 \mathrm{~g}$ was the minimum weight required to allow tagging of a bass with a radio transmitter. The guaranteed battery operation time of the three tag weights are 20,35 , and 50 days respectively. Due to the short battery life expectancy, it was necessary to tag subadult bass year-round, to acquire habitat use and movement information during all seasons.

Fish were captured by electrofishing for radio transmitter implantation. Captured bass of appropriate weight were anesthetized in a clove oil solution following methods described by Peake (1998) (approximately $1.2 \mathrm{~mL}$ clove oil per $20 \mathrm{~L}$ of $\mathrm{H}_{2} \mathrm{O}$ ). Clove oil was used in place of other anesthetic chemicals due to the open nature of the study area, and the possibility that released fish could potentially be captured and consumed by humans. Clove oil has no consumption advisories while tricaine methanesulfonate required up to 21 days following treatment before human consumption is advised (Kelsch and Shields 1996). Surgical transmitter implantation technique follows methods described in Winter (1996). All surgical equipment was sterilized prior to use, and kept in an antiseptic solution (Novisan $\left.{ }^{\circledR}\right)$. Radio transmitters were implanted by making approximately a 2.5 centimeter incision slightly anterior and dorsal to the anal vent. A 
straight needle was utilized to make an exit opening slightly posterior to the actual transmitter in the abdominal cavity to allow the antenna to trail behind unimpeded.

Once the tag was in place in the abdominal cavity, several non-dissolving sutures were added to ensure proper healing and tag retention. After transmitter implantation, bass were kept onboard until swimming ability and proper orientation were regained (Adams et al. 1998). Functionality of transmitters was also checked prior to release. All tagged bass were released as close as possible to their capture location.

\section{Telemetry Sampling}

Initial monitoring of subadult bass locations began within a week of a tagged fish's release and continued until tags were either lost or the batteries expired. An ATS $\otimes$ receiver and hand held loop antenna were used during boat surveys for tagged bass. Telemetry surveys for tagged sub-adult largemouth bass were conducted approximately bi-monthly from July through December 1999, and March through August 2000. To establish tagged fish locations, the Belleville and Willow Island pools were covered by boat, and scanned for tag frequencies on the telemetry receiver. Once a signal was audible, estimates of fish location were made using standard three point triangulation techniques (White and Garrott 1990, Winter 1996). The research vessel was anchored or beached and GPS position, compass bearings to fish location, and time was recorded for tagged bass positions. At the third triangulation point, habitat and water quality measurements were taken, including water temperature, turbidity, depth, conductivity, dissolved oxygen, and visible microhabitat type. Microhabitat was 
categorized as aquatic vegetation, woody debris, or mixed (aquatic vegetation and woody debris).

\section{Habitat Assessment}

Habitat assessment was incorporated into this study in order to establish use versus availability for subadult largemouth bass, as well as to identify certain habitat features as possibly limiting bass production. Our habitat assessment (modified from the stream technique of Bain and Stevenson 1999) was conducted during a one-week period in August 2000. The study design consisted of randomized transect placement within study locations where the most subadult bass had been collected during the electrofishing surveys. Transects were placed within all of the three macrohabitats with three locations in embayments, two locations in tributaries, and two locations within the main channel. A total of 42 transects were completed, six within each of the seven study locations. Transects measured $18 \mathrm{~m}$ in length and microhabitat data was recorded every $2 \mathrm{~m}$, resulting in 420 transect section measurements (Figure 3). Bain and Stevenson (1999) suggested at least 50 transect section measurements be taken in stream habitat, this was increased due to the greater size of the Ohio River system. We utilized a modification of the point method whereby at each point along the transect a $2 \mathrm{~m}$ perpendicular line was run to the point and habitat measurements ( 0.0 to $2.0 \mathrm{~m}$ ) were made along that transect line starting at the shoreline and moving straight out. Information was collected on aquatic vegetation (as a linear measure up to the entire $2 \mathrm{~m}$ ) present at each point and the dominant species along the $2 \mathrm{~m}$ transect point. Identification of vegetation, to genus and species when possible, was made using keys 
by Prescott (1969) and Hotchkiss (1970). Presence of woody debris was also recorded. Visual estimation was used to count individual woody debris pieces and place them into one of four diameter size classes; $1-5 \mathrm{~cm}, 6-10 \mathrm{~cm}, 11-50 \mathrm{~cm}$, and greater than $50 \mathrm{~cm}$. Measurements were made along the $2 \mathrm{~m}$ point line starting at the shoreline and moving straight out until concealing water depth was reached.

\section{Data Analysis}

All statistical analyses on subadult largemouth bass macro and microhabitat use and movement patterns, as well as the habitat assessment data, were performed within the Statistical Analysis System, version 8 (SAS institute1998), with significance set at $\mathrm{P} \leq 0.05$.

Macrohabitat utilization was determined through subadult largemouth bass capture locations from electrofishing survey results. Electrofishing catch data was analyzed to determine whether sub-adult largemouth bass were relatively more abundant in any one macrohabitat type. Electrofishing catch data from the various study locations was evaluated using catch per unit effort (CPUE, number of subadult bass per hour). One-way analysis of variance (ANOVA) was used to determine differences between catch per unit effort values for subadult largemouth bass by location, macrohabitat type, season, and year.

Subadult largemouth bass microhabitat use was identified through telemetry locations. Triangulation of bass point location estimates was made using the program TRIANG (White and Garrott 1990) within SAS. TRIANG calculates the Lenth (1981) maximum likelihood estimator of a transmitter location for three or more compass 
bearings. For estimation of individual fish locations, TRIANG requires the user to enter the standard deviation of the compass bearings (in degrees), which is generally in the range of 0 to 2.0 degrees. We did not measure the bearing standard deviation and as this measure has no influence on the location estimate, we set the value to 1.5 degrees for use in TRIANG. A second program from White and Garrott (1990) using two compass bearings was used for the few instances where topography prevented a third bearing measurement. Individual largemouth bass location estimates from the two White and Garrott programs are given in Universal Transverse Mercator (UTM) coordinates. During data collection largemouth bass locations had been recorded in latitude and longitude, so conversion of point estimates into UTM coordinates was performed prior to triangulation using the Army Corps of Engineers Corpscon ${ }^{\circledR}$ software (1998).

Subadult largemouth bass movement patterns were analyzed through the use of telemetry locations and construction of core-use areas using the minimum convex polygon method (MCP) (Southwood 1966) in the animal home range extension of ArcView ${ }^{\circledR} 3.2$ (Environmental Systems Research Institute 1999). The benefits of utilizing the MCP approach to determine habitat use areas are that no assumptions need to be made about the shape of the home range and outlying locations do not have to be ignored (Southwood 1966). Bass area use maps were created within ArcView using Digital Orthophoto Quarter-Quadrangle 1:12,000 scale images (West Virginia Department of Environmental Protection 1993). At least three locations on an individual subadult largemouth bass were required in order to construct a core use area. Where core use areas of individual bass overlapped dry land, separate land polygon areas 
were calculated and removed from the use area estimate. For comparison purposes, approximate availability areas were quantified for all macrohabitats where tagged fish had been located using on-screen digitizing within ArcView. A one-way ANOVA and the alternative non-parametric test, one-way Kruskal-Wallis (KW) (NPAR1WAY, SAS Institute 1998), were used to identify differences between individual subadult largemouth bass use areas when compared by capture season, year, bass weight and length at capture, and also by area of available habitat within each location.

Additionally, measurements were taken from the core use area maps for each tagged bass between the initial location and the furthest location from it, in order to estimate the range of distances traveled.

The habitat assessment information collected by transect was analyzed to detect differences between macrohabitat types as well as between study locations. The aquatic vegetation data collected for habitat assessment was analyzed using log transformed one-way ANOVA and the KW test statistic. Log transformation of the data was performed in order to account for unequal variances between macrohabitat types (Zar 1999). In addition, the dominant vegetation species was determined within each macrohabitat type and over the entire study area using PROC FREQ in SAS.

Analysis of the woody debris data from habitat assessment transects also utilized log transformed one-way ANOVA and the KW non-parametric statistic. Again, log transformation was performed to deal with unequal variances for the three macrohabitat types. Amounts of woody debris in each diameter size class $(1-5 \mathrm{~cm}, 6-10,11-50$, and $>50$ ) as well as total woody debris were tested individually to determine where differences existed among locations and macrohabitat types. 
Microhabitat use versus availability analysis was performed using telemetry and habitat assessment data. To determine if subadult largemouth bass were using microhabitat in proportion to its availability the chi-square and corrected chi-square goodness of fit tests were used with data pooled across all individuals (White and Garrott 1990, Zar 1999). Subadult largemouth bass microhabitat use was determined from the first telemetry survey location for each tagged individual, with microhabitat identified at the third point estimate. The habitat assessment transect data was used to identify habitat availability within study locations.

\section{Results}

A total of 118 subadult largemouth bass from the Belleville and Willow Island pools of the Ohio River were captured and tagged with either anchor or radio transmitter tags during the course of this study, 67 with anchor tags and 51 with radio transmitters. Anchor tagged bass ranged in length from 123 to $304 \mathrm{~mm}$ (mean 218mm) and wet weight from 23 to $410 \mathrm{~g}$ (mean 177g). Radio tagged bass ranged in length from 166 to $300 \mathrm{~mm}$ (mean $211 \mathrm{~mm}$ ) and wet weight from 64 to $350 \mathrm{~g}$ (mean 133g) (Table 1).

\section{Macrohabitat}

Subadult largemouth bass in the Belleville and Willow Island pools of the Ohio River were most often found in embayment macrohabitats during electrofishing (Table 2) and biotelemetry surveys (Figure 4). Electrofishing results show embayment macrohabitats had the highest CPUE values during all seasons except spring when tributaries had the highest CPUE (Figure 4). During fall the CPUE for embayments (2.3 
subadult bass per hour) was slightly more than twice the CPUE in tributary habitats (1.1). Spring tributary CPUE climbed to 2.7, which was the highest recorded during this study, while embayment CPUE was slightly lower (2.1). Catch per unit effort dropped dramatically during summer months, with embayment CPUE being 1.2 subadult bass per hour, and tributary CPUE only 0.5 (Table 2). During winter months CPUE values continued to decline, with embayments dropping to 0.9 subadult bass per hour and tributaries dropping to zero. A total of 40 hours were spent electrofishing for subadult largemouth bass during the course of this study, resulting in a total catch of 163 subadult largemouth bass (Table 2). No subadult largemouth bass were captured during electrofishing surveys in the main channel of the Ohio River. Throughout the course of this study electrofishing catch rates of largemouth bass were low.

\section{Microhabitat}

Microhabitat availability varied within macrohabitat types. The mixed woody debris and aquatic vegetation microhabitat was most prevalent in embayments, found in $72 \%$ of transects. The mixed habitat type was only found in $33 \%$ of tributary and main channel area transects. There was also a great deal of variation in percentage of mixed habitat in transects between study locations. French Run had the most mixed microhabitat, found in $100 \%$ of transects. Sugarcamp Run had the second highest levels of mixed microhabitat, with $67 \%$ of transects. Indian Run, Swan Run, and one section of the main channel all had $50 \%$ mixed habitat in transects. The two locations with the least mixed microhabitat were Lee Creek and another section of main channel, both with only $17 \%$ of transects containing the mixed microhabitat. 
A mixture of woody debris and aquatic vegetation was identified as the preferred microhabitat of subadult largemouth bass. Overall microhabitat use (telemetry locations) was not in proportion to availability identified through transect point estimation $\left(\chi^{2}=7.5166, P=0.0233\right)$. Further subdivisions of the chi-square identified the mixed aquatic vegetation and woody debris microhabitat category $\left(\chi^{2}=7.2777, \mathrm{P}=0.0070\right)$ as used disproportionately to availability (Table 3). A comparison of percent use versus percent available for each microhabitat category (Table 4) reveals the woody debris and aquatic vegetation habitat types were used in proportion to their availability. The aquatic vegetation habitat type was used in $19 \%$ of telemetry locations while its availability from transects was $21 \%$. The woody debris microhabitat type was used in $41 \%$ of telemetry locations, and its availability in transects was $59 \%$. The mixed woody debris and aquatic vegetation microhabitat category was preferred, used in $41 \%$ of bass locations, while its availability was only $20 \%$.

Over the study period 51 subadult bass were implanted with radio transmitters, however 16 of these fish were never located after their initial release. Analyses of capture size (length and weight) for relocated fish versus unlocated, or lost fish, revealed no significant differences in size demographics (length $P=0.6670$, weight $P=$ 0.7843). Due to difficulties in capturing largemouth bass in winter, the low survival and tag retention in cold water temperatures (Winter 1996), and the tag life limitation for small fish, we were unable to gather telemetry data during the winter season. As a result, microhabitat use versus availability analysis was not performed among seasons due to data limitations. 


\section{Water Quality}

Water quality monitoring activities coincided with electrofishing and biotelemetry surveys. Surface water temperature, dissolved oxygen, turbidity, conductivity, and salinity ranges were similar between study locations (Table 5). Water temperatures ranged from a low of $1.6^{\circ} \mathrm{C}$ to a high of $30.8^{\circ} \mathrm{C}$, both of which were recorded in the main channel outside Lee Creek. The lowest recorded dissolved oxygen levels (5.2 $\mathrm{mg} / \mathrm{L}$ ) were in the main channel of the Ohio River in June of 1999. In study locations where subadult largemouth bass were found, dissolved oxygen was never less than 5.3 $\mathrm{mg} / \mathrm{L}$ thus it does not appear that low oxygen or anoxic conditions in backwater areas is a problem for largemouth bass. Water turbidity levels ranged from a low of 5 NTU's in the main channel of the river outside Lee Creek to a high of 41 NTU's in Lee Creek. Lee creek was generally the most turbid of all locations throughout the study. Conductivity values ranged from $120.0 \mu \mathrm{S}$ in French Run in April 2000 to $884.0 \mu \mathrm{S}$ in the main channel outside Sugarcamp Run in August 1999. For comparison main channel Ohio River water quality values were provided courtesy of Jason Freund (unpublished data), as water quality measurements in this study were taken in conjunction with subadult bass captures and relocations which did not occur in the main channel. Water quality measures were hampered by equipment failure that prevented adequate statistical analysis of this data. On occasions when equipment functioned properly, all water quality measures were similar between macrohabitats (Table 5) and were never found to be a potential biological concern. 


\section{Aquatic Vegetation}

Analysis of aquatic vegetation data collected from transects reveals differences in the amount and species composition of vegetation between study locations (Table 6 and 7), but not between macrohabitat types. In embayments the dominant aquatic plant species was Dianthera americana (water willow) representing $37 \%$ within embayments and $38 \%$ over the entire study area. Dianthera americana was also the dominant species in main channel areas representing $77 \%$ of plant species within the main channel. Tributaries differed in composition from the other two macrohabitats. In tributaries the dominant aquatic vegetation was Myriophyllum exalbescens (milfoil) representing $46 \%$ within tributaries and $20 \%$ overall. One-way log transformed ANOVA of aquatic vegetation amounts between study locations revealed significant differences $(\mathrm{F}=3.33, \mathrm{P}=0.0107)$. The corresponding non-parametric $\mathrm{KW}$ analysis was also significant $(K W=13.2273, P=0.0396)$. ANOVA and $K W$ ranking of study locations according to mean aquatic vegetation yielded similar results. French run had the most aquatic vegetation present. Sugarcamp Run had the second highest levels of aquatic vegetation. There was some disagreement between ANOVA least squares mean and KW mean results for Swan Run and Lee Creek. ANOVA least squares ranked Lee Creek as having the third most vegetation present and ranked Swan Run as having the fourth most vegetative growth. The KW means ranked Swan Run third and Lee Creek fourth in amounts of aquatic vegetation. Both analyses ranked Indian Run fifth in amount of vegetative growth. The two main channel locations had the least amount of aquatic vegetation present according to both testing procedures. There were no detectable differences between aquatic vegetation amounts found in the three 
macrohabitats (one-way log transformed ANOVA, $F=3.18, P=0.1489$; non-parametric analysis, $\mathrm{KW}=3.9286, \mathrm{P}=0.1403$ ). Overall species composition across the entire study area is shown in Table 6.

\section{Woody Debris}

Analysis of woody debris data collected from habitat assessment transects reveals no significant differences between study locations or macrohabitat types for any of the size classes of woody debris or total woody debris. For the $1-5 \mathrm{~cm}$ diameter size class, one-way log transformed ANOVA for macrohabitats was not significant $(\mathrm{P}=$ 0.0672), nor was the KW test $(P=0.1534)$. The results on study locations for the $1-5$ $\mathrm{cm}$ size class also were not significant (ANOVA $\mathrm{P}=0.3380 ; \mathrm{KW} P=0.2529)$. Similarly, for the $6-10 \mathrm{~cm}$ diameter woody debris size class there was no significant difference among macrohabitats (ANOVA $\mathrm{P}=0.9518 ; \mathrm{KW} P=0.8984$ ), or between study locations (ANOVA $\mathrm{P}=0.3999 ; \mathrm{KW} P=0.4650$ ). The $11-50 \mathrm{~cm}$ diameter woody debris size class was also not significantly different between macrohabitats (ANOVA $\mathrm{P}=0.9502 ; \mathrm{KW} P=$ 0.8607 ), or study locations (ANOVA $P=0.4965 ; \mathrm{KW} P=0.6030$ ). The final woody debris size class, $51 \mathrm{~cm}$ diameter and greater, also was not significantly different between macrohabitat types (ANOVA $\mathrm{P}=0.3571 ; \mathrm{KW} P=0.0687$ ) or study locations (ANOVA $P=0.9097 ; \mathrm{KW} P=0.7323$ ). There was also no significant difference between study locations (ANOVA $P=0.4180 ; \mathrm{KW} P=0.4346$ ) or macrohabitat types (ANOVA $P=0.7534 ; \mathrm{KW} \mathrm{P}=0.7382$ ) for the total woody debris from all size classes. Overall microhabitat ANOVA and KW results for both study locations and macrohabitat types are listed in Tables 8 and 9. 


\section{Core-use Areas}

The size of core-use areas for subadult largemouth bass in the Ohio River varied widely, from $88 \mathrm{~m}^{2}$ for fish $48.130 \mathrm{mHz}$ in French Run to $59,400 \mathrm{~m}^{2}$ for fish $48.825 \mathrm{mHz}$ in Indian Run (overall core use area mean $14,861 \mathrm{~m}^{2}$ ) (Table 10). One-way ANOVA and $\mathrm{KW}$ tests were run to detect significant differences in core-use area sizes between bass length, weight, capture season and year, and available area in study locations. Results for core-use areas of bass showed no significant difference between study year, bass length or weight or available habitat area (Table 11). Core-use areas of subadult bass were significantly different between seasons $(F=5.17, P=0.0208$ and $K W=6.7386, P$ $=0.0344)$, with summer use areas being significantly larger than other seasons.

Subadult bass core use areas were smallest during spring. The available area (defined as the approximate area of the study site in which telemetry locations were made for each tagged fish) had no effect on the core-use areas of subadult largemouth bass ( $F=$ 1.92, $P=0.1761$ and $K W=3.2000, P=0.3618)$. The number of relocations on an individual tagged bass did positively affect the size of core use area $(F=7.829, P=$ 0.0135). However, regression analysis suggested only approximately $34 \%$ of the variability in the data was explained by the number of relocations. Available habitat within study locations ranged from $37,638 \mathrm{~m}^{2}$ in Sugarcamp Run to $426,762 \mathrm{~m}^{2}$ in French Run. Core-use areas ranged from $0.02 \%$ to $89.3 \%$ of available habitat in study locations (Table 12).

Based upon telemetry locations, subadult largemouth bass in the Ohio River generally tended to remain within the macrohabitat of their particular nursery embayment or tributary. Rarely did fish venture out into the main channel of the Ohio 
River, and when they did they remained near the mouth of the nursery area. Figures 58 show typical core use areas (defined in white) and movement patterns of subadult largemouth bass found in three locations during the course of this study. Movement patterns are represented as a color scale timeline of fish locations. These images are representative of the core use areas, from small to large, calculated for all tagged bass with at least three locations. The calculated core use area for radio tagged bass $48.331 \mathrm{mHz}$ (Figure 5) was $57,903 \mathrm{~m}^{2}$, the third largest core use area. However all locations were within the central portion of one embayment indicating a "home-body" individual. Radio tagged fish $48.825 \mathrm{mHz}$ had the largest core use area and was also the only individual to be located in the main channel of the Ohio River (Figure 6). The telemetry locations on this bass indicate a "roamer" pattern of movement, showing movements from far back in the tributary out into the main channel. The telemetry locations for both bass $48.735 \mathrm{mHz}$ and $48.754 \mathrm{mHz}$ indicate "home-body" movement patterns, as both core use areas are within a small section of the tributary, near the mouth of the creek (Figure 7). Similarly, radio tagged bass $48.814 \mathrm{mHz}$ and $48.834 \mathrm{mHz}$ core use areas also indicate "home-body" movement patterns (Figure 8). While there is a large difference between their respective core use areas $\left(1,123 \mathrm{~m}^{2}\right.$ for $48.814 \mathrm{mHz}$ and $11,968 \mathrm{~m}^{2}$ for $48.834 \mathrm{mHz}$ ), both these individuals were utilizing a discrete portion of the nursery tributary. The core use areas and movement patterns of all tagged subadult bass are included in the appendix.

As some tagged subadult largemouth bass had too few locations to allow construction of core use areas, linear measurements between the initial telemetry location and the furthest location were also estimated. Similar to the core use areas, 
there was a wide range in the distances subadult largemouth bass moved. The furthest distance estimates ranged from 5 to $750 \mathrm{~m}$ (mean $328.5 \mathrm{~m}$ ) from the initial telemetry location. Four tagged bass traveled less than $100 \mathrm{~m}$ from their initial telemetry location. Four tagged bass also traveled $700 \mathrm{~m}$ or greater from their initial location. The other distance estimates had an even distribution between 100 and 699m.

\section{Discussion}

Subadult largemouth bass in the Belleville and Willow Island pools of the Ohio River generally preferred the embayment macrohabitat type. Electrofishing catch results suggest the embayment macrohabitat is used more by subadult bass than either tributaries or main channel areas during summer, fall, and winter. However, tributaries became more important during spring and data on winter habitat preference was limited due to difficulties collecting fish during winter. This finding identifies embayments as important nursery areas for largemouth bass in the Belleville and Willow Island pools of the Ohio River. The identification of preference for embayment habitat supports the finding by Pearson and Krumholz (1984) that overall largemouth bass abundance in the Ohio River is highest in sections where embayment habitat is most prevalent.

Largemouth bass in other large river habitats have been found to collect (at high concentrations) in a few backwater areas during winter, bypassing other off channel areas entirely (Carlson 1992, Pitlo 1992, and Raibley et al. 1997). In the Ohio River largemouth bass do not appear to concentrate in a few specific backwater areas, as bass electrofishing CPUE remained low throughout the entire study period and no single backwater area had significantly higher winter catch rates. It appears that instead of high concentrations of bass in a few off channel areas, the Ohio River during 
winter can be characterized as having lower concentrations in many backwater (embayment and tributary) habitats. One study location, French Run, had the highest overall catch rates. This embayment had unique habitat, in the form of wholesubmerged trees and tree stumps, while woody cover in other locations tended to be in the form of snags.

A mixture of woody debris and aquatic vegetation was identified as the preferred microhabitat of subadult largemouth bass in the Ohio River. This finding supports the conclusions of Scheidegger and Bain (1995) that woody cover and aquatic vegetation are important components of centrarchid nursery habitat. Within the Ohio River, increases in habitat heterogeneity have also been identified as having a positive correlation to fish abundance and productivity (Thorp 1992). In other aquatic systems habitat heterogeneity has been identified as a factor leading to increased recruitment, growth, and survival (Caselle and Warner 1996; Power 1992). The identification of mixed habitat as utilized in $41 \%$ of bass locations, when compared to its availability of only $20 \%$ in transects identifies this microhabitat as a potentially limiting factor in largemouth bass production within the Ohio River. The microhabitat category woody debris also appears to be important to subadult bass, as it was utilized in $41 \%$ of telemetry locations. As there does not appear to be a lack of woody debris within the Ohio River (there were no significant differences between study locations or macrohabitats), in the Belleville and Willow Island pools lack of aquatic vegetation could be limiting largemouth bass production. While use of this microhabitat was proportional to its availability, this microhabitat becomes important in the formation of mixed microhabitat. The absence of aquatic vegetation along transect points was usually the 
reason for a lack of mixed microhabitat. Woody debris was the most prevalent form of cover, yet its use was in proportion to its availability. Since there is not a shortage of woody cover, in order to increase microhabitat heterogeneity it is necessary to increase aquatic vegetation growth. It appears that habitat heterogeneity is an important factor in determining subadult largemouth bass habitat selection, as suggested by Thorp (1992) in regards to the Ohio River fishery as a whole.

In many study locations, vegetation was patchy and sparse. Growth of aquatic plants may be reduced in the Ohio River by the high levels of sedimentation, which reduces water clarity. The result of significant differences in aquatic vegetation amounts between study locations, but not macrohabitats, may be due to low sample sizes, as in general the main channel had much less vegetative growth than embayment and tributary habitats. Identification of the mixed microhabitat as preferred also gives us some insight into why embayment macrohabitats are preferred within this study area, as the mixed microhabitat was most prevalent in embayments. Of the embayment study locations French Run consistently had the highest bass catch rates. Interestingly, French Run also had the highest amount of mixed microhabitat. Further analysis of the microhabitat assessment results also offers some explanation about the absence of subadult bass in the main channel of the Ohio River. Of the two stretches of main channel in which transects were conducted, one had 50\% mixed microhabitat, while the other had only $17 \%$. Both of these main channel areas offer poorer habitat heterogeneity when compared to embayment areas (with $72 \%$ mixed microhabitat).

The core-use areas of subadult largemouth bass in the Ohio River system appear to be drastically different than those of adult or juvenile bass as identified in 
other home range studies. Adult largemouth bass have exhibited use of $61-122 \mathrm{~m}$ diameter, or approximately $2,921 \mathrm{~m}^{2}-11,684 \mathrm{~m}^{2}$, home areas during spring and summer (Hasler and Wisby 1958, Lewis and Flickinger 1967). The mean core use area in the present study $\left(14,861 \mathrm{~m}^{2}\right)$ was similar to the larger estimated home ranges in other studies. However, four Ohio River fish had core use areas larger than reported in the earlier studies. Core use areas also differed by site. Two sites (Indian Run and Lee Creek) had mean core use areas that exceeded those reported in earlier studies (Hasler and Wisby 1958, Lewis and Flickinger 1967) and two sites (French Run and Sugarcamp Run) had mean core use areas within the range earlier reported. These results suggest some Ohio River sites are better quality, requiring smaller ranges, than others.

Research on subadult bass populations in a reservoir has suggested most move less than 60 meters in the first two years of life (Copeland and Noble 1994). The furthest distance estimates of tagged subadult largemouth bass in the Ohio River, with a mean of $328.5 \mathrm{~m}$, show most individuals traveled more than $60 \mathrm{~m}$ from their initial telemetry location during the course of this study. However, our findings do corroborate those of Woodward (1996), who found juvenile largemouth had well defined home ranges and infrequent movements outside the home area. The wide range of core use areas found for subadult bass in this region of the Ohio River does allow for the possibility of "home body" and "roaming" individuals as proposed in other studies (Parker 1956, Hasler 1958, Moody 1960, Wanjala et al. 1986). Within the Belleville pool of the Ohio River a concurrent adult bass study has also identified distinct "home body" and "roaming" individuals (Jason Freund- personal communication). However, with the subadult largemouth bass there does not appear to be distinct groups of homebodies 
and wide ranging individuals, but rather a wide range from relatively small core use areas to quite large. The larger core use areas of subadult largemouth bass within the Ohio River compared to other home range studies, suggests habitat quality may be poorer here than in other aquatic systems. Subadult bass in the Ohio River may need to travel further in order to meet their basic requirements of food and cover, thus using larger home areas.

The identification of summer use areas as being significantly larger than other seasons may further indicate poorer overall habitat quality in the Ohio River during the critical growing season. Davies and Houston (1984) noted that fish movement changes with changes in the abundance and distribution of resources. Huey and Pianka (1981) suggested fish movement should increase when resource density is low and/or unpredictable. Additionally, the wide range of core use area sizes found in the Ohio River may be related to the variability in microhabitat quality between study locations, as embayment or tributary size, and fish size, had no effect on core use area. The number of telemetry relocations on an individual subadult bass did affect the size of its associated core use area; regression explains about $34 \%$ of the variability seen among core use are sizes. The variability in core use areas caused by the number of relocations may in part be due to the number of relocations that it is possible to obtain prior to battery failure. This high variability may be a problem common to studies dealing with small individuals. As technology continues to improve biotelemetry equipment and transmitter battery life is extended, the affect of the number of relocations on core use areas may be reduced or eliminated as it will be possible to collect more relocations on each tagged individual before battery failure. 
Embayment macrohabitat and mixed woody debris and aquatic vegetation microhabitat are preferred by subadult largemouth bass within the Belleville and Willow Island pools of the Ohio River. The identification of critical macro and microhabitat within the study area provides fishery managers with much needed baseline information which may be used to formulate an effective bass management strategy. This information may also be useful as a mitigation tool when evaluating future plans for river floodplain alteration. Despite larger core use areas than previously found in other systems, a localized approach may be useful to managers. Biotelemetry locations show movement within the nursery embayment or tributary and only limited activity outside the nursery area. If managers were to implement some remedial habitat improvements in embayment watersheds it may have a beneficial effect on the Ohio River largemouth bass population as a whole. Identifying ways to reduce the high sedimentation rates in embayments and tributaries would improve water clarity and allow increased aquatic vegetation growth. The results shown here suggest stocking is not an effective option for improving largemouth bass abundance in this region of the Ohio River, unless habitat improvements are also implemented. The limited availability of the preferred mixed woody debris and aquatic vegetation microhabitat could result in a lack of cover for stocked fish and contribute to high mortality rates and/or high dispersal rates such as those suggested by Janney (2001). Habitat assessment results when considered with the findings of high dispersal or mortality of stocked largemouth bass in two Ohio River embayments in a concurrent study (Janney 2001) may also suggest poorer general habitat quality in the Ohio River than other systems. In other pond or impoundment systems stocked bass may not need to move out of the stocking location, as previous 
studies in these systems have shown limited bass movements (Hasler and Wisby 1958; Lewis and Flickinger 1967; Mesing and Wicker 1986). The concurrent Ohio River adult largemouth bass habitat use study in the Belleville pool has also found some movements by tagged bass of several miles within a relatively short period of time (Hartman 2001). Again, the greater movements of bass than has been shown in other studies may be a result of generally poorer habitat quality within the Ohio River.

During the course of this study, 16 subadult largemouth bass were lost following transmitter implantation. For microhabitat use analyses it was assumed that these fish were lost due to tag failure. The smallest model radio transmitter used early in this study was discontinued by the manufacturer due to low battery life (Kyle Hartmanpersonal communication), facilitating thoughts that tag failure may be responsible for unlocated fish. If fish had died the transmitters should have been located in the same position during repeated surveys and this was not the case with any fish tagged during the study. A possible contributing factor to the number of lost fish was a problem with signal attenuation discovered during the course of this study. While signals in shallow water areas were audible for a reasonably great distance, signal loss occurred at just below 2 meters in depth. With this finding comes the possibility that bass with active transmitters moving into main channel deep water habitat would be less likely to be located. For embayment and tributary habitats the loss of signal with increasing depth is not thought to be a great problem. If the 16 lost subadult bass were utilizing deepwater habitats it could mean this habitat is more important than suggested by the present study's findings. However, main channel telemetry surveys were conducted and only one tagged subadult bass was ever located in the main channel. In addition, 
the minimum navigation channel depth of $2.7 \mathrm{~m}$ suggests radio tagged bass would have been located in at least the upper portion of the main channel water column, had they been present and the transmitter batteries functional. The CPUE results for the main channel habitat supports the telemetry results, indicating this habitat is infrequently utilized by subadult largemouth bass.

In this study we use the term "core use area" instead of "home range" when referring to biotelemetry results. Due to the short battery life of appropriately sized radio transmitters for use in subadult fish, use of home range was deemed inappropriate. The calculated core use areas are over a much shorter time period than is generally found in home range studies. As radio transmitter capabilities increase and size decreases, more thorough home range studies will be possible during the critical subadult life stage.

Throughout this study electrofishing catch rates remained extremely low. As a result, a somewhat high cutoff length of $305 \mathrm{~mm}$ was selected as the subadult largemouth bass maximum length in an attempt to increase our sample size. While largemouth bass growth is highly variable and age determination was not performed on the subadult bass in this study, other studies have used similar cutoff lengths for categorizing bass as juvenile/subadult or adult. Carlson (1992) utilized a $305 \mathrm{~mm}$ cutoff as the minimum length of an adult largemouth bass in the Hudson River. Woodward (1996) performed aging on subadult largemouth bass in a North Carolina reservoir and determined that age- 2 bass in spring were immature, ranged in length from $200-250 \mathrm{~mm}$ (TL), and would be mature the next spring. Only five subadult largemouth bass tagged with radio transmitters and included in statistical analyses were actually greater than 
$275 \mathrm{~mm}$ in length. Removal of those five largest tagged fish did not affect the results (use by habitat $P=0.1965$, use by length $P=0.2318$, use by weight $P=0.3651$, use by year $P=0.2349$, and use by season $P=0.0263$ ).

This study reveals many unanswered questions regarding early life history of largemouth bass in the Ohio River. Even the study location with the highest subadult bass catch rates, French Run, still had low catches compared to other systems. French run also had the highest amount of preferred mixed microhabitat. It is therefore likely that additional factors are keeping the Ohio River largemouth bass population at low levels. One possibility is low abundance and/or quality of prey. A model by Hixon (1980) predicts fish territory size might increase with decreasing food availability. McFadden (1969) and Slaney and Northcote (1974) report that fish territory size is inversely related to food abundance. Additional research into the forage preferences of subadult largemouth bass could identify another limiting factor in Ohio River bass recruitment and offer an additional explanation for the large core use areas and generally low densities of bass exhibited here. It is likely that limited habitat availability is not the only reason for low abundance in this large river system. Instead, as in many other aquatic ecosystems, it is most likely the cumulative effect of many biotic and abiotic factors, which ultimately regulates recruitment and thus abundance within the Ohio River. 


\section{Literature Cited}

Adams, N.S., D.W. Rondorf, S.D. Evans, J.E. Kelly, and R.W. Perry. 1998. Effects of surgically and gastrically implanted radio transmitters on swimming performance and predator avoidance of juvenile chinook salmon (Oncorhynchus tshawytscha). Canadian Journal of Fisheries and Aquatic Sciences 55 no4:781-787.

Anderson, O. 1984. Optimal foraging by largemouth bass in structured environments. Ecology 65:851-861.

Bain, M.B., J.T. Finn and H.E. Booke. 1988. Streamflow regulation and fish community structure. Ecology 69:382-392.

Bain, M.B. and N.J. Stevenson, eds. 1999. Aquatic habitat assessment: common methods. American Fisheries Society, Bethesda, MD.

Bayley, P.B. 1995. Understanding large river-floodplain ecosystems. Bioscience 45:153158.

Brietenbach, R. and G. Peterson (eds). 1980. Fish and wildlife management work group appendix, Great River Environmental Action Team II (GREAT II). U.S. Fish and Wildlife Service, Rock Island, IL.

Carlson, M.D. 1992. Importance of wintering refugia to the largemouth bass fishery in the Hudson River Estuary. Journal of Freshwater Ecology 7(2):173-180.

Carmichael, G.J., J.R. Tomasso, B.A. Simco, and K.B. Davis. 1984. Confinement and water quality-induced stress in largemouth bass. Transactions of the American Fisheries Society 113:767-777.

Caselle, J.E., and R.R. Warner. 1996. Variability in recruitment of coral reef fishes: the importance of habitat at two spatial scales. Ecology 77:2488-2504.

Copeland, J.R. 1992. Evidence for site fidelity in young-of-year largemouth bass: implications for reservoir fisheries management. North Carolina State University. Raleigh, NC. Master's Thesis.

Copeland, J.R. and R.L. Noble. 1994. Movements by young-of-year and yearling largemouth bass and their implications for supplemental stocking. North American Journal of Fisheries Management 14:119-124.

Davies, N.B. and A.I. Houston. 1984. Pages 148-169 in J.R. Krebs and N.B. Davies eds. Behavioural ecology. Sinauer, Sunderland. 
Diana, J.S. 1983. Oxygen consumption by largemouth bass under constant and fluctuating thermal regimes. Canadian Journal of Zoology 61:1892-1895.

Environmental Systems Research Institute. 1999. ARCVIEW. Version 3.2.

Environmental Systems Research Institute, Redlands, CA.

Fullerton, A.H., J.E. Garvey, R.A. Wright, and R.A. Stein. 2000. Overwinter growth and survival of largemouth bass: interactions among size, food, origin, and winter severity. Transactions of the American Fisheries Society 129:1-12.

Garvey, J.E., and R.A. Stein. 1998. Linking bluegill and gizzard shad prey assemblages to growth of age-0 largemouth bass in reservoirs. Transactions of the American Fisheries Society 127:70-83.

Garvey, J.E., R.A. Wright, and R.A. Stein. 1998. Overwinter growth and survival of age0 largemouth bass (Micropterus salmoides): revisiting the role of body size. Canadian Journal of Fisheries and Aquatic Sciences 55:2414-2424.

Gent, R., J. Pitlo, and T. Boland. 1995. Largemouth bass response to habitat and water quality rehabilitation in a backwater of the upper Mississippi River. North American Journal of Fisheries Management 15:784-793.

Hartman, K.J. 2001. Studies of largemouth bass habitat use, and stocking evaluation in West Virginia waters of the Ohio River. Final report to WV Division of Natural Resources, Charleston, WV. 180pp.

Hasler, A.D. and W.J. Wisby. 1958. The return of displaced largemouth bass and green sunfish to a "home" area. Ecology 39:289-293.

Hixon, M.A. 1980. Food production and competitor density as the determinants of feeding terrotory size. American Naturalist 115:510-530.

Hotchkiss, N. 1970. Common underwater and floating-leaved plants of the United States and Canada. Dover publications, NY.

Huey, R.B. and E.R. Pianka. 1981. Ecological consequences of foraging mode. Ecology 62:991-999.

Irwin, E.R., R.L. Noble, and J.R. Jackson. 1997. Distribution of age-0 largemouth bass in relation to shoreline landscape features. North American Journal of Fisheries Management 17:882-893.

Jackson, J.R., and R.L. Noble. 1995. Selectivity of sampling methods for juvenile largemouth bass in assessments of recruitment processes. North American Journal of Fisheries Management 15:408-418. 
Janney, E.C. 2001. Evaluation of a fall stocking of adult and intermediate largemouth bass (Micropterus salmoides) into two Ohio River embayments. West Virginia University, Morgantown, WV. Master's Thesis.

Kelsch, S.W. and B. Shields. 1996. Page 125-126 in B.R. Murphy and D.W. Willis, eds. Fisheries Techniques. American Fisheries Society, Bethesda, MD.

Kinsolving, A. D. and M.B. Bain. 1993. Fish assemblage recovery along a riverine disturbance gradient. Ecological Applications 3:531-544.

Kohler, C.C, R.J. Sheehan, and J.J. Sweatman. 1993. Largemouth bass hatching success and first-winter survival in two Illinois reservoirs. North American Journal of Fisheries Management 13:125-133.

Lenth, R.V. 1981. On finding the source of a signal. Technometrics 23: 149-154.

Lewis, W.M. and S. Flickinger. 1967. Home range tendency of the largemouth bass (Micropterus salmoides). Ecology 48:1020-1023.

McCauley, R.W. and D.M. Kilgour. 1990. Effect of air temperature on growth of largemouth bass in North America. Transactions of the American Fisheries Society 119:276-281.

McFadden, J.T. 1969. Pages 312-329. In T.G. Northcote (ed.). Symposium on salmon and trout in streams, Institute of Fisheries, University of British Columbia, Vancouver.

Mesing, C. L., and A. M. Wicker. 1986. Home range spawning migrations, and homing of radio-tagged Florida largemouth bass in two central Florida lakes. Transactions of the American Fisheries Society 115:286-295.

Miranda, L.E. and W.D. Hubbard. 1994. Length-dependant winter survival and lipid composition of age-0 largemouth bass in Bay Springs reservoir, Mississippi. Transactions of the American Fisheries Society 123:80-87.

Miranda, L.E., W.L. Shelton, and T.D. Bryce. 1984. Effects of water level manipulation on abundance, mortality, and growth of young-of-year largemouth bass in West Point reservoir, Alabama-Georgia. North American Journal of Fisheries Management 4:314320.

Montgomery, R. 1991. Restoring large river fishery resources: the Mississippi interstate cooperative resource agreement. Fisheries 16:44-47.

Moody, H.L. 1960. Recaptures of adult largemouth bass from the St. Johns River, Florida. Transactions of the American Fisheries Society 89:295-300. 
Novotny, D.W. and G.R. Priegel. 1974. Electrofishing boats: improved designs and operational guidelines to increase the effectiveness of boom shockers. Page 249 in Fisheries Techniques, B.R. Murphy and D.W. Willis, eds. American Fisheries Society, Bethesda, MD.

Olson, M.H. 1996. Ontogenetic niche shifts in largemouth bass: variability and consequences for first-year growth. Ecology 77:179-190.

Parker, R.A. 1956. A contribution to the population dynamics and homing behavior of northern Wisconsin lake fishes. Ph.D. Dissertation. University of Wisconsin, Madison.

Peake, S. 1998. Sodium Bicarbonate and Clove Oil as Potential Anesthetics for Nonsalmonid Fishes. North American Journal of Fisheries Management 18:919-924.

Pearce, J.E. 1989. The Ohio River. University press of Kentucky, Lexington, KY.

Pearson, W.D. and L.A. Krumholz. 1984. Distribution and status of Ohio River fishes. University of Louisville. Louisville, Kentucky.

Pine, W.E., S.A. Ludsin, and D.R. DeVries. 2000. First-summer survival of largemouth bass cohorts: is early spawning really best? Transactions of the American Fisheries Society 129:504-513.

Pitlo, J. 1992. An evaluation of largemouth bass populations in the upper Mississippi River. lowa Department of Natural Resources, Federal Aid to Fish Restoration, Project F-109-R, Fianl Report, Des Moines.

Post, D.M., J.F. Kitchell, and J.R. Hodgson. 1998. Interactions among adult demography, spawning date, growth rate, predation, overwinter mortality, and the recruitment of largemouth bass in a northern lake. Canadian Journal of Fisheries and Aquatic Sciences 55:2588-2600.

Power, M.E. 1992. Habitat heterogeneity and the functional significance of fish in river food webs. Ecology 73:1675-1688.

Prescott, G.W. 1969. How to know the aquatic plants. Wm. C. Brown Company Publishers, Dubuque, IA.

Raibley, P.T., K.S. Irons, T.M. O'Hara, K.D. Blodgett, and R.E. Sparks. 1997. Winter habitats used by largemouth bass in the Illinois River, a large river-floodplain ecosystem. North American Journal of Fisheries Management 17:401-412.

SAS Institute.1998. SAS/STAT user's guide. Version 8. First edition. SAS institute, Cary, NC. 
Scheidegger, K.J. and M.B. Bain. 1995. Larval fish distribution and microhabitat use in free-flowing and regulated rivers. Copeia no1:125-35.

Schell, S.A., D.J. Bright, J.A. Marshall, and M.A. Greenlee. 1996. Ohio River Recreational Use Survey 1992-1993. Ohio Department of Natural Resources. Federal Aid in Sportfish Restoration Project F-69-P.

Slaney, P.A. and T.G. Northcote. 1974. Effects of prey abundance on density and territorial behavior of young rainbow trout (Salmo gairdneri) in laboratory stream channels. Journal of Fisheries Research Board of Canada 31:1201-1209.

Southwood, T.R.E. 1966. Ecological methods. Butler and Tanner Ltd., London, UK.

Thorp, J.H. 1992. Linkage between islands and benthos in the Ohio River, with implications for riverine management. Canadian Journal of Fisheries and Aquatic Sciences 49:1873-1882.

Twedt, D.J., W.C. Guest, and B.W. Farquhar. 1992. Selective dipnetting of largemouth bass during electrofishing. North American Journal of Fisheries Management 12:609611.

U.S. Army Corps of Engineers. 1998. Corpscon. Version 5.11.04. U.S. Army Corps of Engineers Topographic Center, Alexandria, VA.

US Department of the Interior, Fish and Wildlife Service, U.S. Department of Commerce, Bureau of the Census. 1993. 1991 National survey of fishing, hunting, and wildlife associated recreation in West Virginia. U.S. Government Printing Office, Washington, DC.

Wanjala, B.S., J.C. Tash, W.J. Matter, and C.D. Ziebell. 1986. Food and habitat use by different sizes of largemouth bass (Micropterus salmoides) in Alamo Lake, Arizona. Journal of Freshwater Ecology 3:359-369.

White, G.C. and R.A. Garrott. 1990. Analysis of wildlife radio-tracking data. Academic press, Inc. San Diego, CA.

Winter, J. 1996. Page 555-585 in B.R. Murphy and D.W. Willis, eds. Fisheries Techniques. American Fisheries Society, Bethesda, MD.

Woodward, K.O. 1996. Reservoir movements of sub-adult largemouth bass (Micropterus salmoides). North Carolina State University. Raleigh, NC.

West Virginia Department of Environmental Protection. 1993. Technical Applications in Geographic Information Systems office, Nitro, WV.

Zar, J.H. 1999. Biostatistical analysis. Prentice-Hall Inc. Upper Saddle River, NJ. 
Table 1. Length and weight information from all anchor and radio transmitter tagged subadult largemouth bass.

\begin{tabular}{|c|c|c|c|c|c|c|c|c|c|c|c|}
\hline Anchor Tag & Length & Weight & Anchor Tag & Length & Weight & Anchor Tag & Length & Weight & Radio Tag & Length & Weight \\
\hline 000 & 303 & 410 & 111 & 280 & 259 & 236 & 176 & 76 & 48.501 & 252 & 205 \\
\hline 004 & 212 & 100 & 117 & 169 & 54 & 242 & 123 & . & 48.520 & 288 & 300 \\
\hline 005 & 291 & 362 & 123 & 153 & 49 & 244 & 262 & 236 & 48.541 & 296 & 300 \\
\hline 011 & 167 & 51 & 132 & 144 & 32 & 246 & 207 & . & 48.561 & 249 & 195 \\
\hline 012 & 182 & 77 & 134 & 131 & 23 & 248 & 232 & 240 & 48.581 & 195 & 110 \\
\hline 018 & 281 & 270 & 140 & 213 & 117 & & & & 48.601 & 184 & 80 \\
\hline 021 & 297 & 375 & 145 & 280 & 155 & Radio Tag & Length & Weight & 48.621 & 201 & 115 \\
\hline 024 & 151 & 34 & 149 & 135 & . & 48.090 & 174 & 70 & 48.660 & 192 & 95 \\
\hline 026 & 246 & 212 & 150 & 295 & 395 & 48.100 & 172 & 70 & 48.681 & 187 & 80 \\
\hline 035 & 304 & 405 & 169 & 189 & 76 & 48.110 & 178 & 85 & 48.705 & 272 & 275 \\
\hline 036 & 284 & 330 & 172 & 193 & 86 & 48.120 & 185 & 93 & 48.715 & 278 & 280 \\
\hline 037 & 215 & 122 & 176 & 266 & 286 & 48.130 & 193 & 95 & 48.725 & 200 & 110 \\
\hline 038 & 147 & 34 & 184 & 284 & 310 & 48.140 & 187 & 85 & 48.735 & 300 & 350 \\
\hline 042 & 235 & 160 & 186 & 302 & 405 & 48.150 & 183 & 90 & 48.754 & 175 & 64 \\
\hline 046 & 273 & 248 & 189 & 134 & 27 & 48.181 & 191 & 110 & 48.764 & 185 & 76 \\
\hline 048 & 291 & 359 & 199 & 178 & 68 & 48.191 & 220 & 145 & 48.774 & 182 & 80 \\
\hline 054 & 132 & . & 202 & 256 & 236 & 48.200 & 200 & 125 & 48.783 & 190 & 90 \\
\hline 055 & 265 & 234 & 203 & 181 & . & 48.290 & 171 & 66 & 48.804 & 201 & 95 \\
\hline 059 & 247 & 203 & 206 & 170 & 63 & 48.301 & 191 & 65 & 48.814 & 190 & 84 \\
\hline 072 & 154 & 41 & 206 & 196 & 111 & 48.310 & 166 & 70 & 48.825 & 230 & 181 \\
\hline 073 & 151 & 41 & 207 & 276 & 290 & 48.321 & 180 & 90 & 48.834 & 220 & 154 \\
\hline 074 & 202 & 109 & 209 & 257 & 249 & 48.331 & 177 & 80 & 48.844 & 249 & 208 \\
\hline 081 & 192 & 77 & 218 & 140 & 34 & 48.340 & 171 & 71 & 48.854 & 228 & 150 \\
\hline 082 & 157 & 45 & 219 & 300 & 351 & 48.350 & 207 & 115 & 48.864 & 225 & 236 \\
\hline 085 & 139 & 30 & 221 & 276 & 290 & 48.360 & 251 & 110 & 48.901 & 202 & 100 \\
\hline 086 & 288 & 350 & 222 & 256 & 232 & 48.371 & 218 & 125 & 48.941 & 196 & 85 \\
\hline 092 & 294 & 380 & 224 & 190 & 80 & 48.401 & 242 & 165 & 48.961 & 194 & 100 \\
\hline 096 & 216 & 104 & 227 & 273 & . & 48.421 & 298 & 290 & & & \\
\hline 097 & 187 & 77 & 230 & 168 & 51 & 48.441 & 210 & 105 & & & \\
\hline 098 & 268 & 315 & 232 & 153 & . & 48.461 & 230 & 145 & & & \\
\hline 111 & 243 & 174 & 236 & 146 & 34 & 48.481 & 229 & 140 & & & \\
\hline
\end{tabular}


Table 2. Summary of electrofishing effort and catch results of subadult largemouth bass.

\begin{tabular}{|c|c|c|c|c|c|c|c|}
\hline Year & Season & $\begin{array}{c}\text { Seasonal } \\
\text { Electrofishing }\end{array}$ & Macrohabitat Type & $\begin{array}{c}\text { Subadult } \\
\text { Bass Catch }\end{array}$ & $\begin{array}{c}\text { Electrofishing } \\
\text { (Hours) }\end{array}$ & Macrohabitat & $\begin{array}{c}\text { Habitat } \\
\text { totals }\end{array}$ \\
\hline \multirow[t]{6}{*}{1998} & Summer & 7.50 & Main channel & 0 & 6.00 & Main Channel & 11.25 \\
\hline & & & Embayment & 1 & 0.25 & & \\
\hline & & & Tributary & 1 & 1.25 & Embayment & 14.50 \\
\hline & Fall & 10.50 & Main channel & 0 & 2.25 & & \\
\hline & & & Embayment & 12 & 3.50 & Tributary & 14.25 \\
\hline & & & Tributary & 15 & 4.75 & & \\
\hline \multirow[t]{12}{*}{1999} & Winter & 2.25 & Main channel & 0 & 0.25 & & \\
\hline & & & Embayment & 7 & 1.00 & & \\
\hline & & & Tributary & 0 & 1.00 & & \\
\hline & Spring & 7.00 & Main channel & 0 & 1.50 & & \\
\hline & & & Embayment & 14 & 2.25 & & \\
\hline & & & Tributary & 30 & 3.25 & & \\
\hline & Summer & 4.00 & Main channel & 0 & 1.00 & & \\
\hline & & & Embayment & 3 & 1.00 & & \\
\hline & & & Tributary & 6 & 2.00 & & \\
\hline & Fall & 2.75 & Main channel & 0 & 0.25 & & \\
\hline & & & Embayment & 22 & 2.00 & & \\
\hline & & & Tributary & 2 & 0.50 & & \\
\hline \multirow[t]{10}{*}{2000} & Winter & 1.00 & Main channel & 0 & 0.00 & & \\
\hline & & & Embayment & 7 & 1.00 & & \\
\hline & & & Tributary & 0 & 0.00 & & \\
\hline & Spring & 4.00 & Main channel & 0 & 0.00 & & \\
\hline & & & Embayment & 18 & 2.50 & & \\
\hline & & & Tributary & 11 & 1.50 & & \\
\hline & Summer & 1.00 & Main channel & 0 & 0.00 & & \\
\hline & & & Embayment & 14 & 1.00 & & \\
\hline & & & Tributary & $\underline{0}$ & $\underline{0.00}$ & & \\
\hline & & & Totals & 163 & $\overline{40.00}$ & & \\
\hline
\end{tabular}


Table 3. Results of chi-square analysis of microhabitat categories for use in proportion to availability.

Test

overall microhabitat use

without aquatic vegetation

without mixed habitat type

\section{Chi-square statistic}

7.5166

7.2777

0.2760

1
0.0233

0.0070

0.5993 
Table 4. Comparison of microhabitat utilization from telemetry locations with habitat availability from transect data in sites within the Willow Island and Belleville pools of the Ohio River.

\begin{tabular}{lccc}
\hline Microhabitat type & \% Use & \% Available & Selection \\
\hline aquatic vegetation & 18.75 & 20.87 & $*$ \\
woody debris & 40.63 & 59.19 & $*$ \\
mixed vegetation and woody debris & 40.63 & 19.94 & prefer \\
& & & \\
\hline
\end{tabular}

${ }^{*}$ Denotes habitat use was in the expected proportion to availability. 
Table 5. Water quality results for all study locations sampled for subadult largemouth bass in the Willow Island and Belleville pools of the Ohio River.

\begin{tabular}{|c|c|c|c|c|c|c|c|c|c|}
\hline \multirow[b]{2}{*}{ Location } & \multicolumn{2}{|c|}{$\begin{array}{l}\text { Temperature } \\
\text { (C) }\end{array}$} & \multirow{2}{*}{$\begin{array}{c}\text { Dissolved Oxygen } \\
\text { (mg/L) } \\
\text { Low }\end{array}$} & \multicolumn{2}{|c|}{$\begin{array}{c}\text { Turbidity } \\
\text { (NTU) }\end{array}$} & \multicolumn{2}{|c|}{$\begin{array}{l}\text { Conductivity } \\
\text { (uS) }\end{array}$} & \multicolumn{2}{|c|}{$\begin{array}{l}\text { Salinity } \\
\text { (ppm) }\end{array}$} \\
\hline & Low & High & & Low & High & Low & High & Low & High \\
\hline French Run & 7.8 & 28.4 & 7.65 & & lata & 120.0 & 392.4 & 0.1 & 1 \\
\hline Indian Run & 4.2 & 29.9 & 6.1 & 7 & 29 & 176.0 & 596.0 & 0.1 & 0.3 \\
\hline Lee Creek & 9.9 & 30.7 & 5.3 & 16 & 41 & 148.0 & 602.0 & 0.1 & 0.3 \\
\hline Main channel near Lee Creek & 1.6 & 30.8 & 5.2 & 5 & 24 & 200.4 & 690.0 & \multicolumn{2}{|c|}{ no data } \\
\hline Sugarcamp Run & 6.2 & 14.0 & 8.5 & 12 & 14 & 472.0 & 480.0 & 0.3 & 0.3 \\
\hline Main channel by Sugarcamp Run & 2.1 & 30.6 & 5.2 & 7 & 26 & 212.9 & 884.0 & \multicolumn{2}{|c|}{ no data } \\
\hline Swan Run & 5.1 & 30.6 & 7.1 & 11 & 34 & 262.0 & 596.0 & 0.1 & 0.3 \\
\hline
\end{tabular}


Table 6. Comparison of means for aquatic vegetation amounts using KruskalWallis and log transformed ANOVA.

\begin{tabular}{lcccc}
\hline Location & Least squares mean & ANOVA rank & Kruskal-Wallis mean & KW rank \\
\hline French Run & 0.64070260 & 1 & 34.500000 & 1 \\
Sugarcamp Run & 0.35948737 & 2 & 25.500000 & 2 \\
Swan Run & 0.20205348 & 4 & 22.500000 & 3 \\
Lee Creek & 0.24678756 & 3 & 19.166667 & 4 \\
Indian Run & 0.16439439 & 5 & 18.833333 & 5 \\
Main Channel 2 & 0.06291473 & 6 & 18.000000 & 6 \\
Main Channel 1 & 0.00353155 & 7 & 12.000000 & 7 \\
\hline
\end{tabular}


Table 7. Dominant plant species in all macrohabitats sampled as part of subadult largemouth bass habitat use studies in the Ohio River 1998-2000.

\begin{tabular}{lccccc}
\hline \multicolumn{1}{c}{ Species } & $\begin{array}{c}\text { Common } \\
\text { Name }\end{array}$ & $\begin{array}{c}\text { \% of total for } \\
\text { embayments }\end{array}$ & $\begin{array}{c}\text { of total for } \\
\text { tributaries }\end{array}$ & $\begin{array}{c}\text { \% t total for main } \\
\text { channel }\end{array}$ & $\begin{array}{c}\text { \% over entire } \\
\text { study area }\end{array}$ \\
\hline Dianthera americana & Water willow & 37.23 & 16.67 & 76.92 & 38.28 \\
Kalmia polifolia & Swamp laurel & 20.21 & 0.00 & 15.38 & 15.63 \\
Myriophyllum exalbescens & Milfoil & 15.96 & 45.83 & 0.00 & 20.31 \\
Tolypella & macroalgae & 10.64 & 0.00 & 0.00 & 7.81 \\
Peltandra virginica & Arrow arum & 9.57 & 0.00 & 0.00 & 7.03 \\
Lemna minor & Duckweed & 6.38 & 0.00 & 0.00 & 4.69 \\
Elatine triandra & Water wort & 0.00 & 20.83 & 0.00 & 2.34 \\
Juncus effusus & Rush & 0.00 & 16.67 & 0.00 & 3.13 \\
Unknown & & 0.00 & 0.00 & 7.69 & 0.78 \\
\hline
\end{tabular}


Table 8. Comparison of Kruskal-Wallis and log transformed ANOVA results for habitat assessment across study locations.

\begin{tabular}{lcccc}
\hline Feature & $\mathbf{F}$ & $\mathbf{P}$-value & KW & P-value \\
\hline aquatic vegetation amount & 3.33 & 0.0107 & 13.2273 & 0.0396 \\
wood $>50 \mathrm{~cm}$ & 0.34 & 0.9097 & 3.5876 & 0.7323 \\
wood $11-50 \mathrm{~cm}$ diameter & 0.91 & 0.4965 & 4.5476 & 0.603 \\
wood 6-10cm diameter & 1.07 & 0.3999 & 5.6378 & 0.465 \\
wood 1-5cm diameter & 1.18 & 0.3380 & 7.8033 & 0.2529 \\
total wood & 1.04 & 0.4180 & 5.8991 & 0.4346 \\
\hline
\end{tabular}


Table 9.Comparison of log transformed ANOVA and Kruskal-Wallis results for habitat assessment data by macrohabitat type.

\begin{tabular}{lcccc}
\hline Feature & $\mathbf{F}$ & $\mathbf{P}$-value & KW & P-value \\
\hline aquatic vegetation amount & 3.18 & 0.1489 & 3.9286 & 0.1403 \\
wood $>50 \mathrm{~cm}$ diameter & 1.35 & 0.3571 & 5.3571 & 0.0687 \\
wood 11-50cm dia. & 0.05 & 0.9502 & 0.3000 & 0.8607 \\
wood 6-10cm dia. & 0.05 & 0.9518 & 0.2143 & 0.8984 \\
wood 1-5cm dia. & 5.72 & 0.0672 & 3.7500 & 0.1534 \\
total wood & 0.30 & 0.7534 & 0.6071 & 0.7382 \\
& & & & \\
& & & & \\
\hline
\end{tabular}


Table 10. Comparison of core-use area sizes from biotelemetry locations for subadult largemouth bass in the Ohio River.

\begin{tabular}{llcccc}
\hline Fish ID & Location & Use area (m2) & \# Relocations & $\begin{array}{c}\text { Means by location } \\
\left.\text { Core use areas } \mathbf{( m}^{2}\right)\end{array}$ & $\begin{array}{c}\text { Overall Mean Core use } \\
\text { area }(\mathbf{m})\end{array}$ \\
\hline 48.130 & French Run & 88.38 & 3 & 10600.36 & 14861.25 \\
48.705 & French Run & 931.58 & 3 & & \\
48.200 & French Run & 1027.87 & 4 & 16496.67 & \\
48.814 & Lee Creek & 1122.52 & 4 & \\
48.754 & Lee Creek & 1367.11 & 6 & \\
48.191 & French Run & 2234.94 & 4 & \\
48.150 & French Run & 2591.37 & 7 & \\
48.110 & French Run & 3764.13 & 5 & \\
48.854 & Sugarcamp Run & 4753.83 & 4 & \\
48.290 & French Run & 8544.00 & 3 & \\
48.735 & Lee Creek & 9016.13 & 9 & \\
48.120 & French Run & 9515.11 & 3 & \\
48.834 & Lee Creek & 11968.43 & 5 & \\
48.140 & French Run & 19402.85 & 5 & \\
48.331 & French Run & 57903.39 & 6 & \\
48.844 & Lee Creek & 59009.17 & 7 & \\
48.825 & Indian Run & 59400.41 & 10 & & \\
\hline
\end{tabular}


Table 11. Results of ANOVA and Kruskal-Wallis statistical analysis for core use areas of subadult largemouth bass across fish length, weight, capture season and year, and available area of habitat.

\begin{tabular}{lcccc}
\hline Test & $\mathbf{F}$ & P-value & KW & P-value \\
\hline bass length & 10.39 & 0.2394 & 15.0392 & 0.4486 \\
bass weight & 3.98 & 0.3764 & 15.2941 & 0.4304 \\
bass capture season & 5.17 & 0.0208 & 6.7386 & 0.0344 \\
bass capture year & 1.62 & 0.2230 & 2.5128 & 0.1129 \\
available area in study location & 1.92 & 0.1761 & 3.2000 & 0.3618 \\
\hline
\end{tabular}


Table 12. Percentage of available habitat used in subadult bass core use areas in study locations.

\begin{tabular}{llccc}
\hline Fish ID & Location & Use area $\left(\mathbf{m}^{2}\right)$ & Habitat Area $\left(\mathbf{m}^{2}\right)$ & $\%$ of avail. used \\
\hline 48.130 & French Run & 88.38 & 426762.19 & 0.02 \\
48.705 & French Run & 931.58 & 426762.19 & 0.22 \\
48.200 & French Run & 1027.87 & 426762.19 & 0.24 \\
48.814 & Lee Creek & 1122.52 & 235204.16 & 0.48 \\
48.191 & French Run & 2234.94 & 426762.19 & 0.52 \\
48.754 & Lee Creek & 1367.11 & 235204.16 & 0.58 \\
48.150 & French Run & 2591.37 & 426762.19 & 0.61 \\
48.110 & French Run & 3764.13 & 426762.19 & 0.88 \\
48.290 & French Run & 8544.00 & 426762.19 & 2.00 \\
48.120 & French Run & 9515.11 & 426762.19 & 2.23 \\
48.735 & Lee Creek & 9016.13 & 235204.16 & 3.83 \\
48.140 & French Run & 19402.85 & 426762.19 & 4.55 \\
48.834 & Lee Creek & 11968.43 & 235204.16 & 5.09 \\
48.854 & Sugarcamp Run & 4753.83 & 37638.37 & 12.63 \\
48.331 & French Run & 57903.39 & 426762.19 & 13.57 \\
48.844 & Lee Creek & 59009.17 & 235204.16 & 25.09 \\
48.825 & Indian Run & 59400.41 & 66506.88 & 89.31 \\
\hline
\end{tabular}




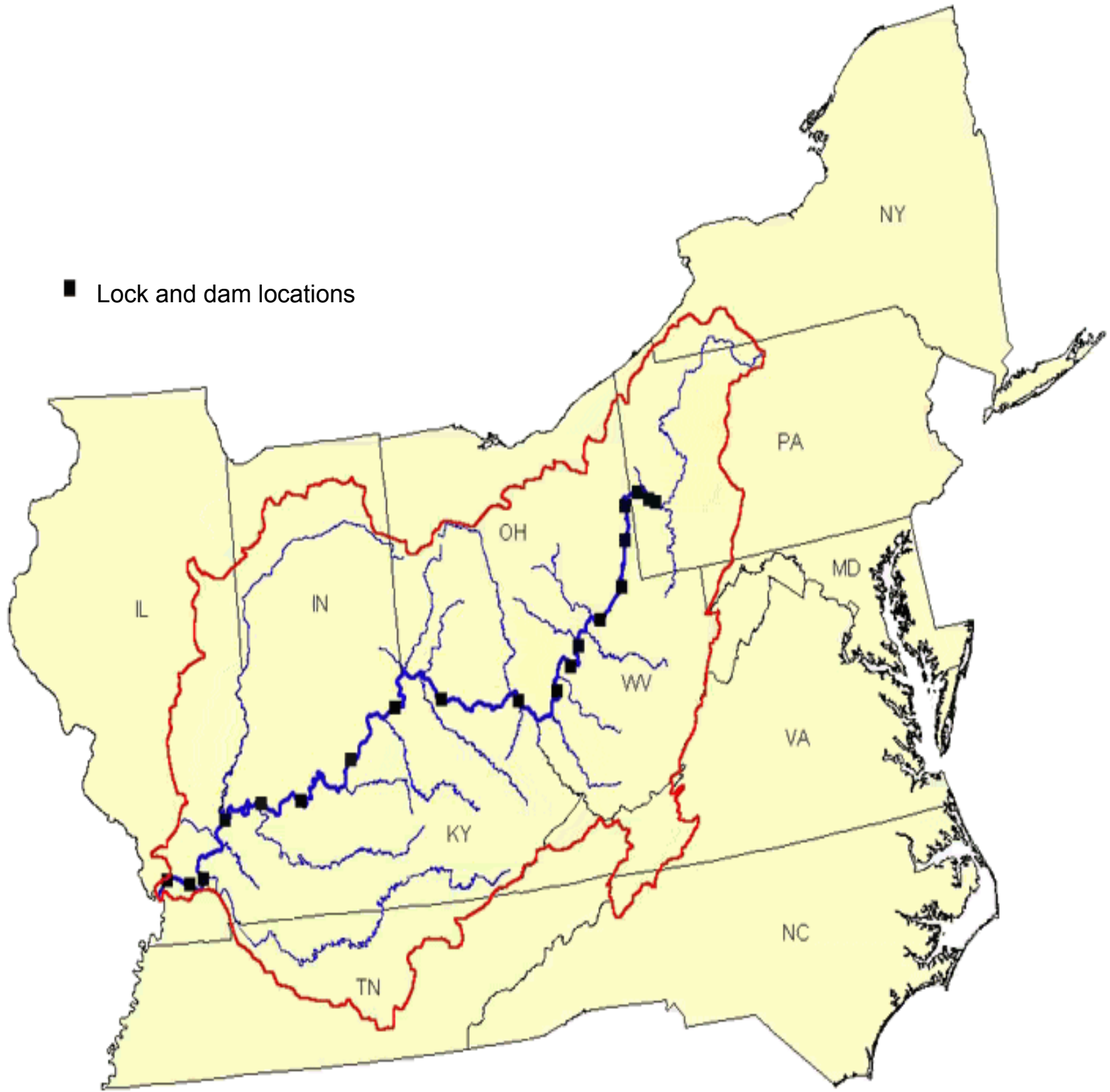

Map created by the Ohio River Valley Water Sanitation Commission (ORSANCO) www.orsanco.org

Figure 1. Map of the Ohio River showing placement of lock and dams and basin drainage. 


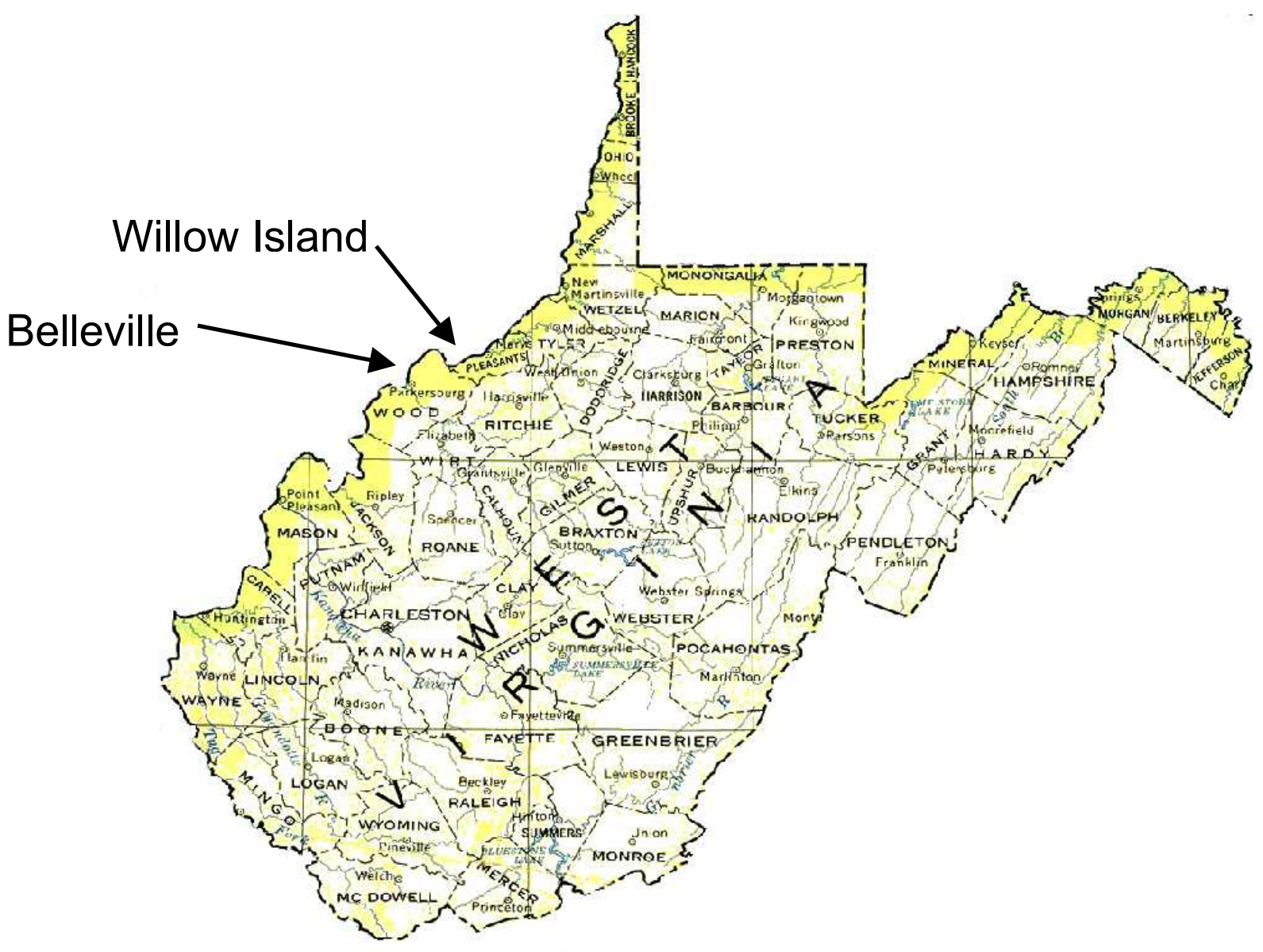

Figure 2. Location of Ohio River study areas. 


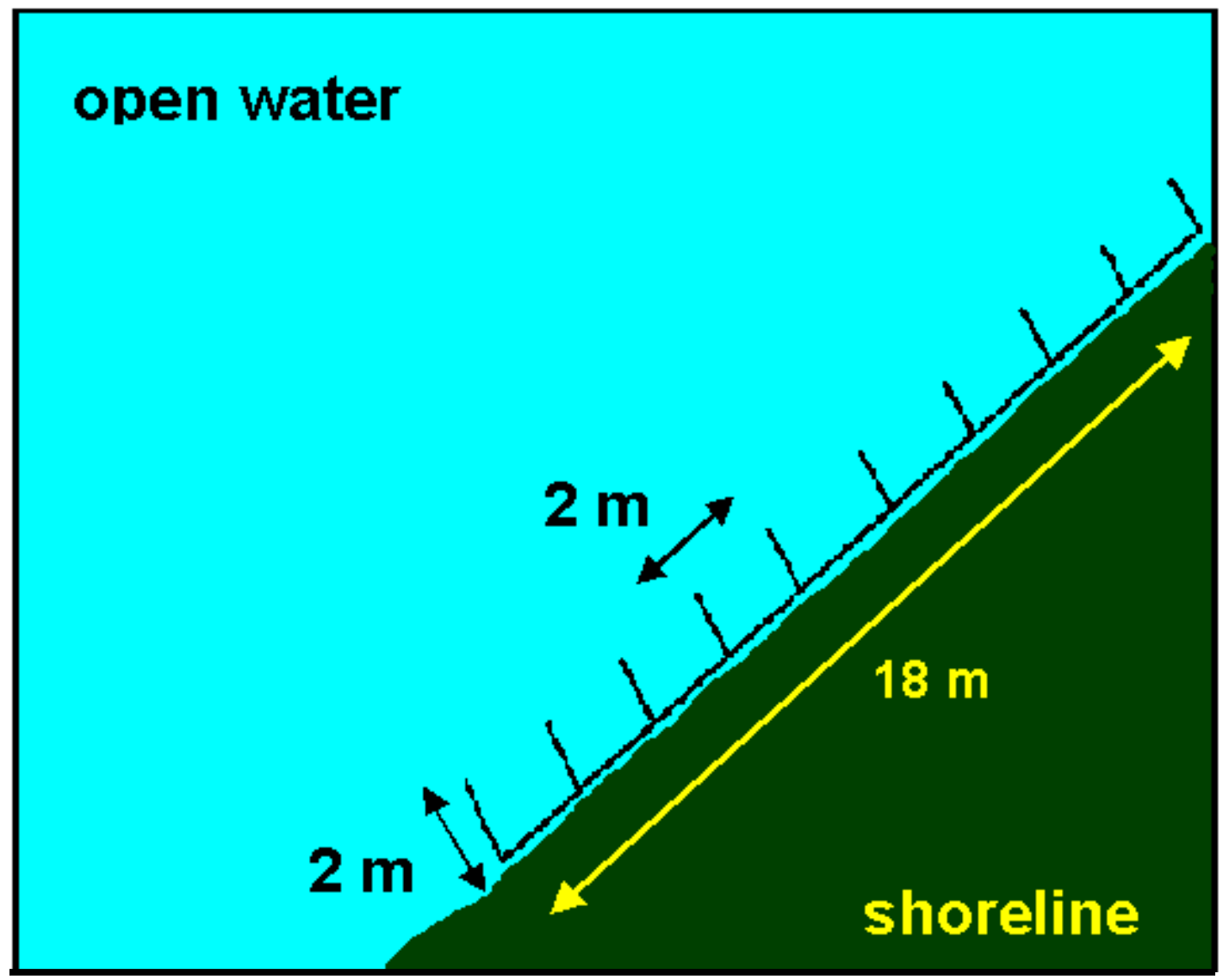

Figure 3. Transect design for habitat availability determination. 


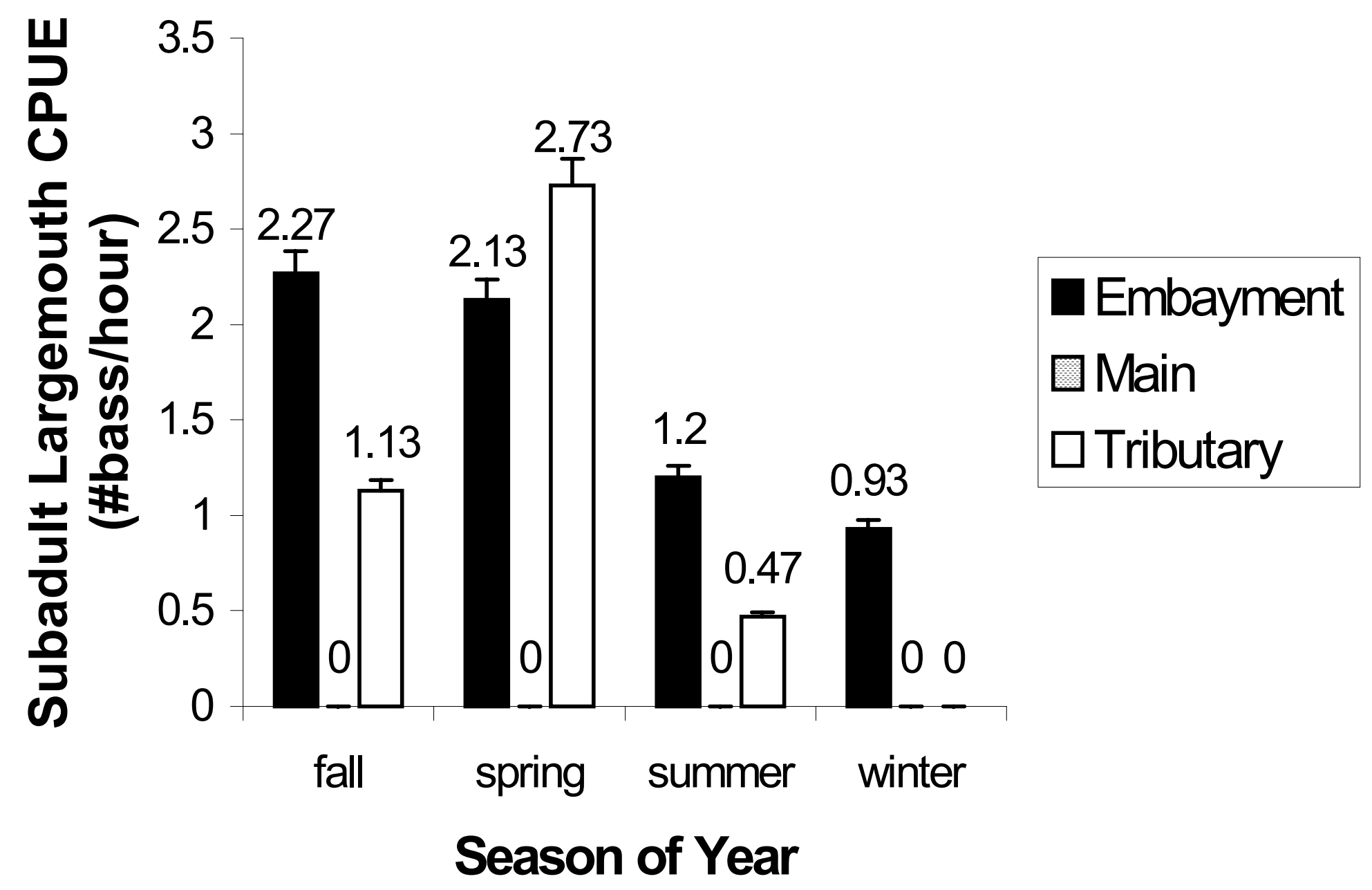

Figure 4. Seasonal subadult largemouth bass CPUE (bass per hour) by macrohabitat type in boat electrofishing surveys. 

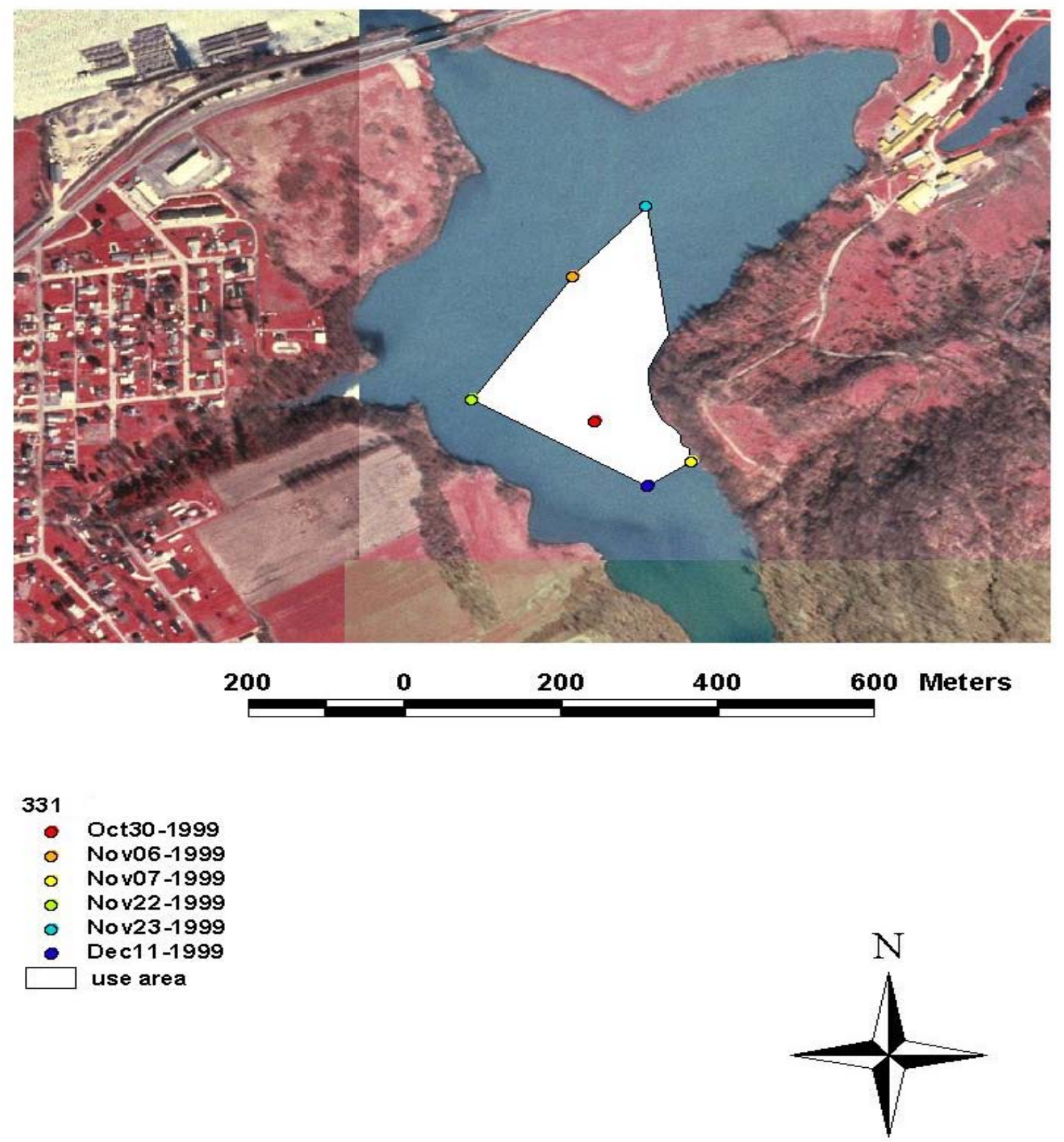

Figure 5. Radio telemetry locations and core use area within the French Run embayment for the subadult largemouth bass tagged with the frequency $48.331 \mathrm{mHz}$. 

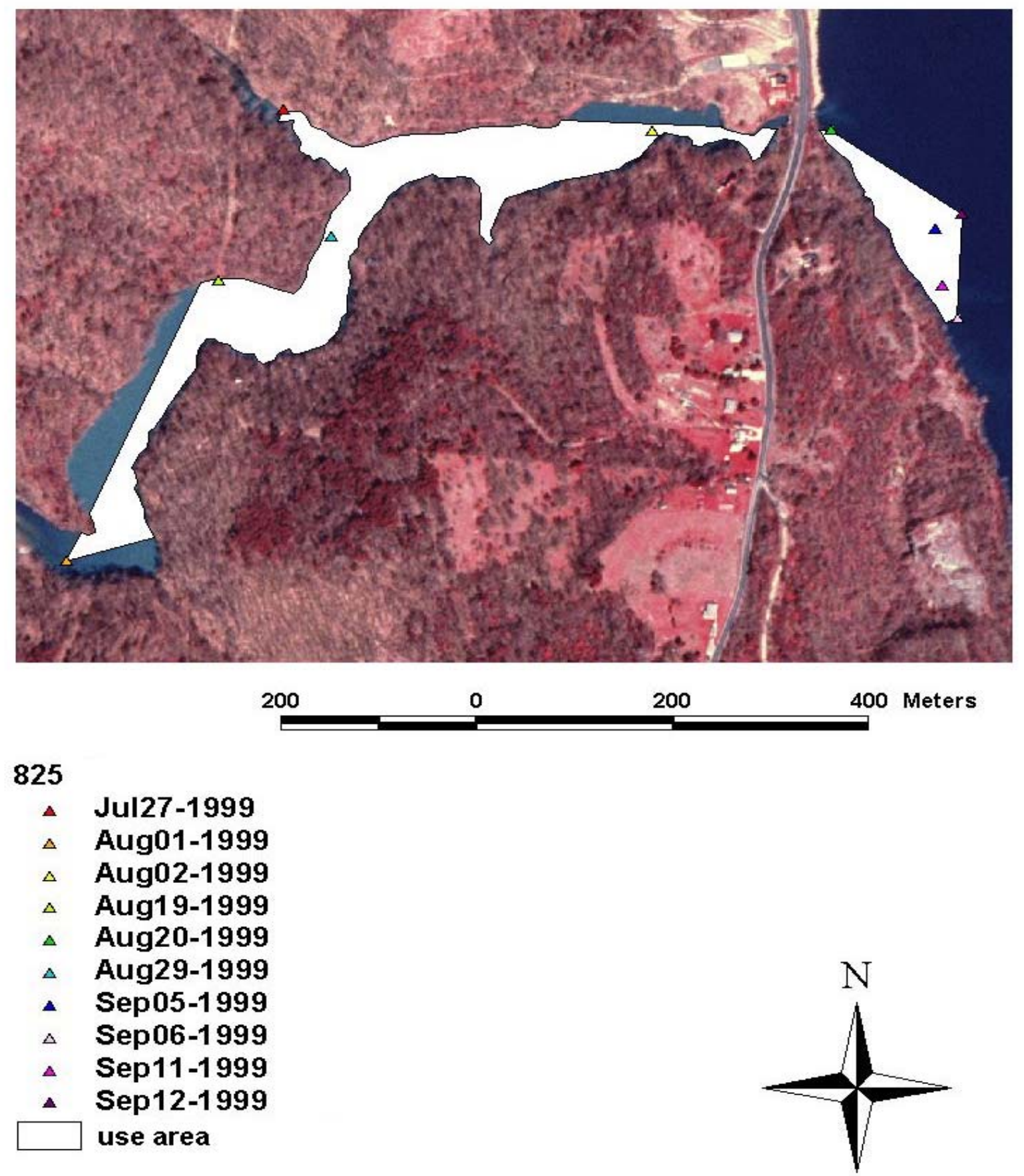

Figure 6. Radio telemetry locations and core use area within the Indian Run tributary for the subadult largemouth bass tagged with the frequency $48.825 \mathrm{mHz}$. 


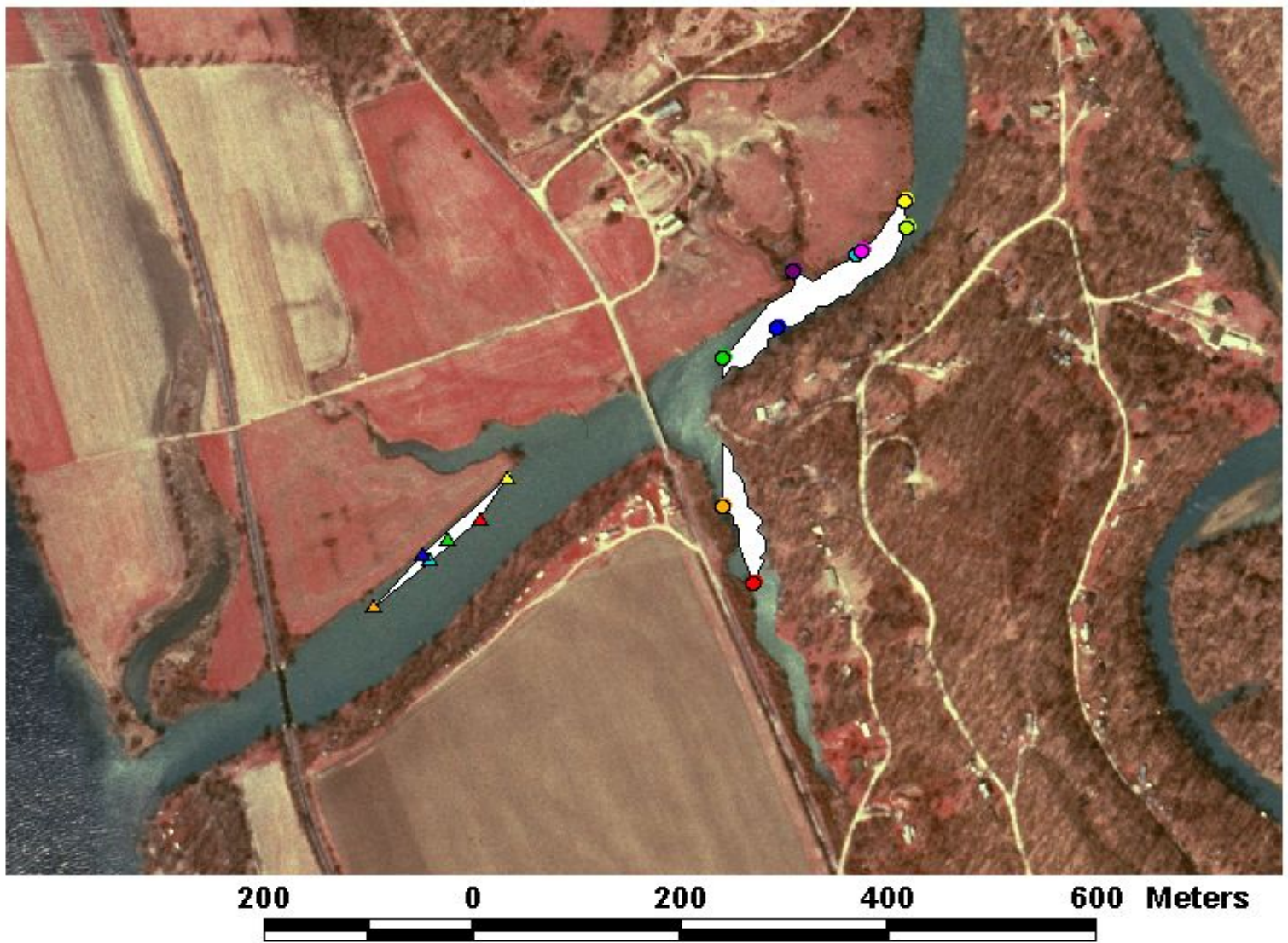

\begin{tabular}{cl}
735 & \\
\hline & May10-2000 \\
$\circ$ & May11-2000 \\
$\circ$ & May18-2000 \\
$\circ$ & May19-2000 \\
$\circ$ & Jun03-2000 \\
$\circ$ & Jun04-2000 \\
\hline & Jun20-2000 \\
\hline & Jun22-2000 \\
\hline & Jun23-2000 \\
\hline & use area \\
\hline 754 & May10-2000 \\
$\triangle$ & May11-2000 \\
$\triangle$ & May18-2000 \\
$\triangle$ & May19-2000 \\
$\triangle$ & Jun03-2000 \\
$\triangle$ & Jun04-2000 \\
\hline & use area
\end{tabular}

Figure 7. Radio telemetry locations and core use area within the Lee Creek tributary for the subadult largemouth bass tagged with the frequencies 48.735 and $48.754 \mathrm{mHz}$. 

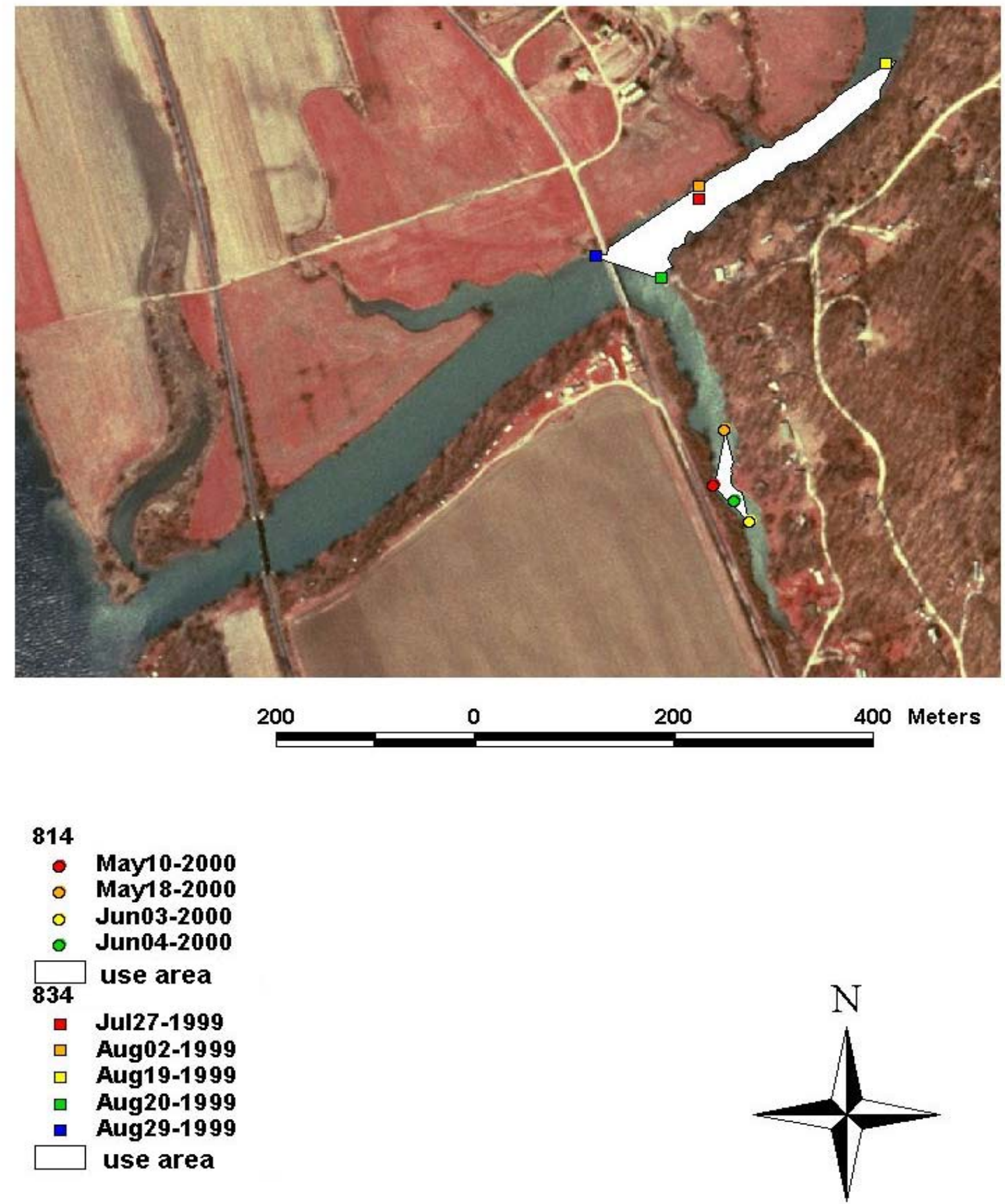

Figure 8. Radio telemetry locations and core use areas within the Lee Creek tributary for the subadult largemouth bass tagged with the frequencies 48.814 and $48.834 \mathrm{mHz}$. 

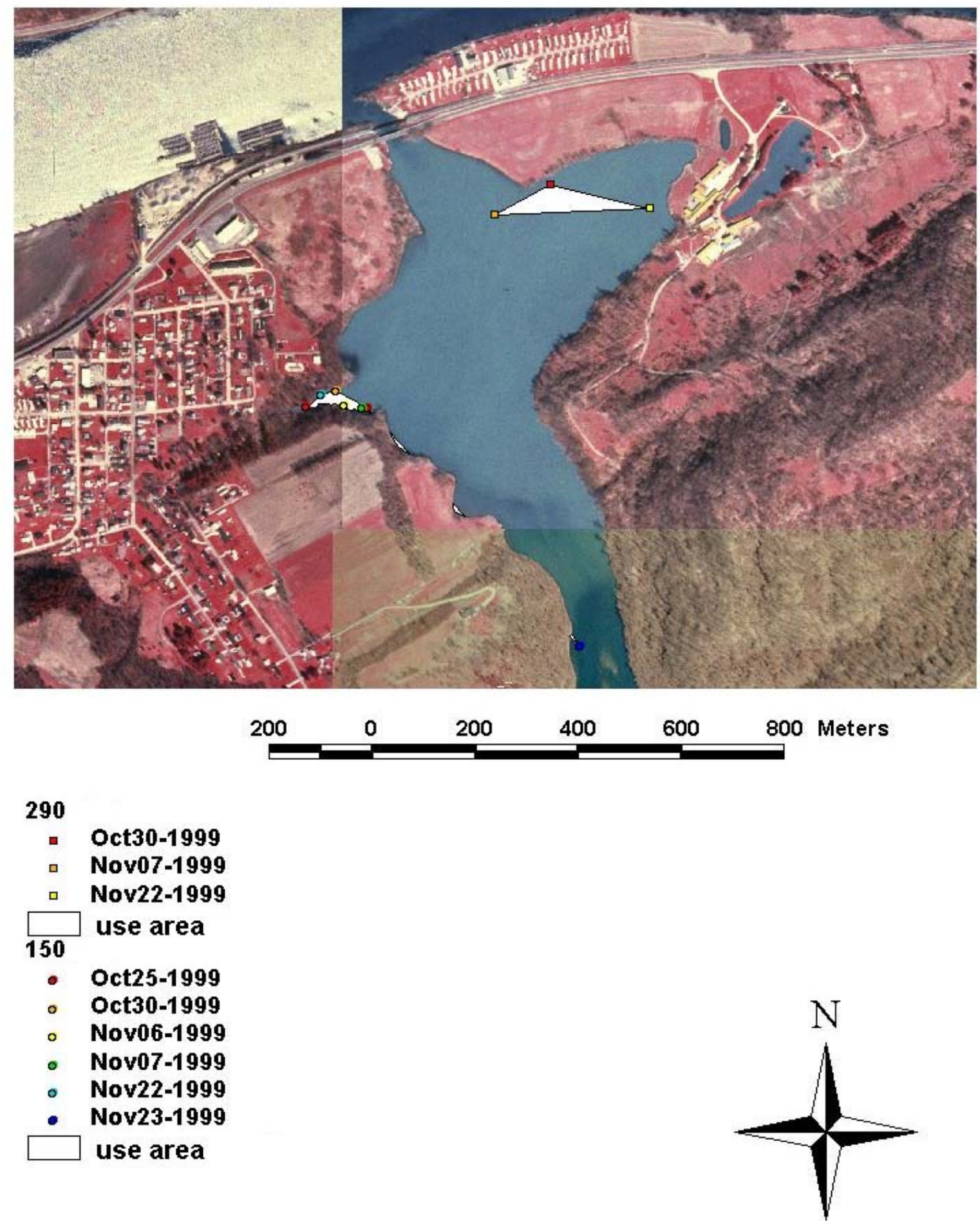

Figure A-1. Radio tlemetry locations and core use areas within the French Run embayment for the subadult largemouth bass with freqeuncies 48.290 and $48.150 \mathrm{mHz}$. 


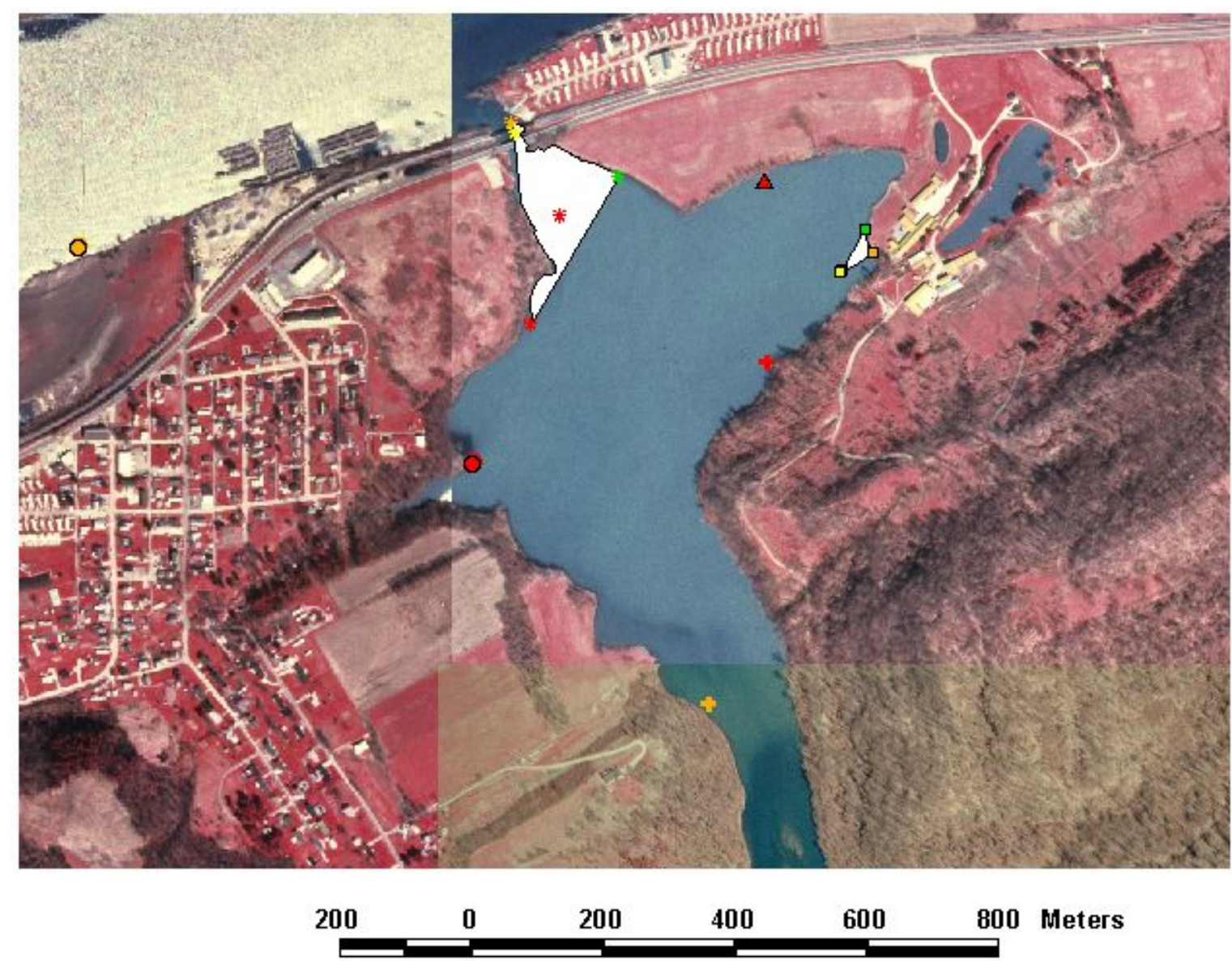

\begin{aligned} 200 & \\ $\square &$ Oct22-1999 \\ $\square &$ Nov06-1999 \\ $\square &$ Nov07-1999 \\ $\square &$ Nov22-1999 \\ \hline & use area \\ \hline 140 & \\ $* &$ Oct30-1999 \\ $* &$ Nov06-1999 \\ & Nov07-1999 \\ $* &$ Nov22-1999 \\ \hline & use area \\ \hline 301 & \\ + & Oct30-1999 \\ $* &$ Nov07-1999 \\ 090 & \\ \hline & Oct25-1999 \\ $\circ &$ Oct30-1999 \\ 360 & \\ $\triangle &$ Oct22-1999 \end{aligned}

Figure A-2. Radio telemtery locations and core use areas within the French Run embayment for the subadult largemouth bass tagged with frequencies $48.200,48.140$, $48.301,48.090$, and $48.360 \mathrm{mHz}$. 

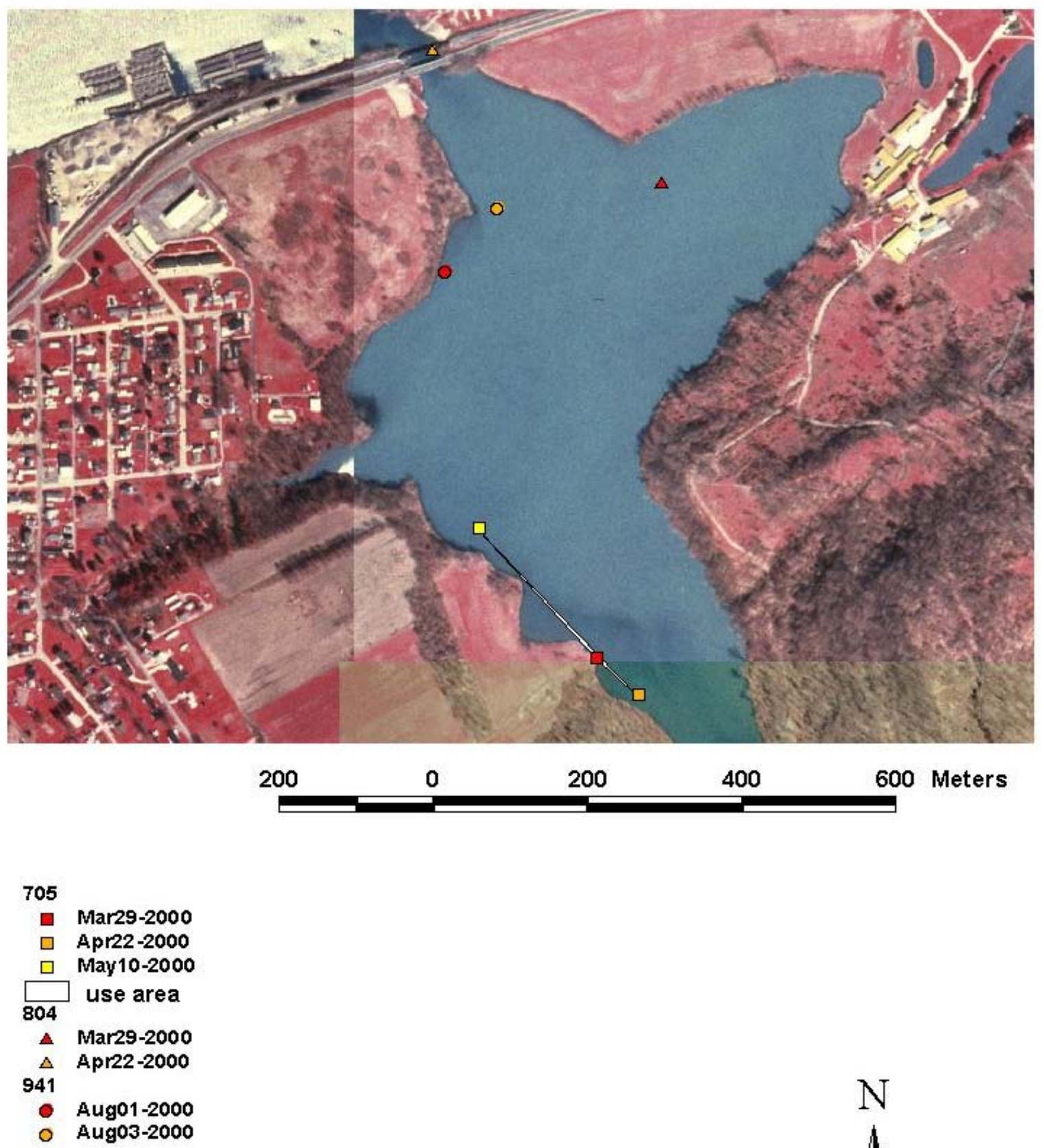

Figure A-3. Radio telemetry locations and core use area within the French Run embayment for the subadult largemouth bass tagged with frequencies $48.705,48.804$, and $48.941 \mathrm{mHz}$. 


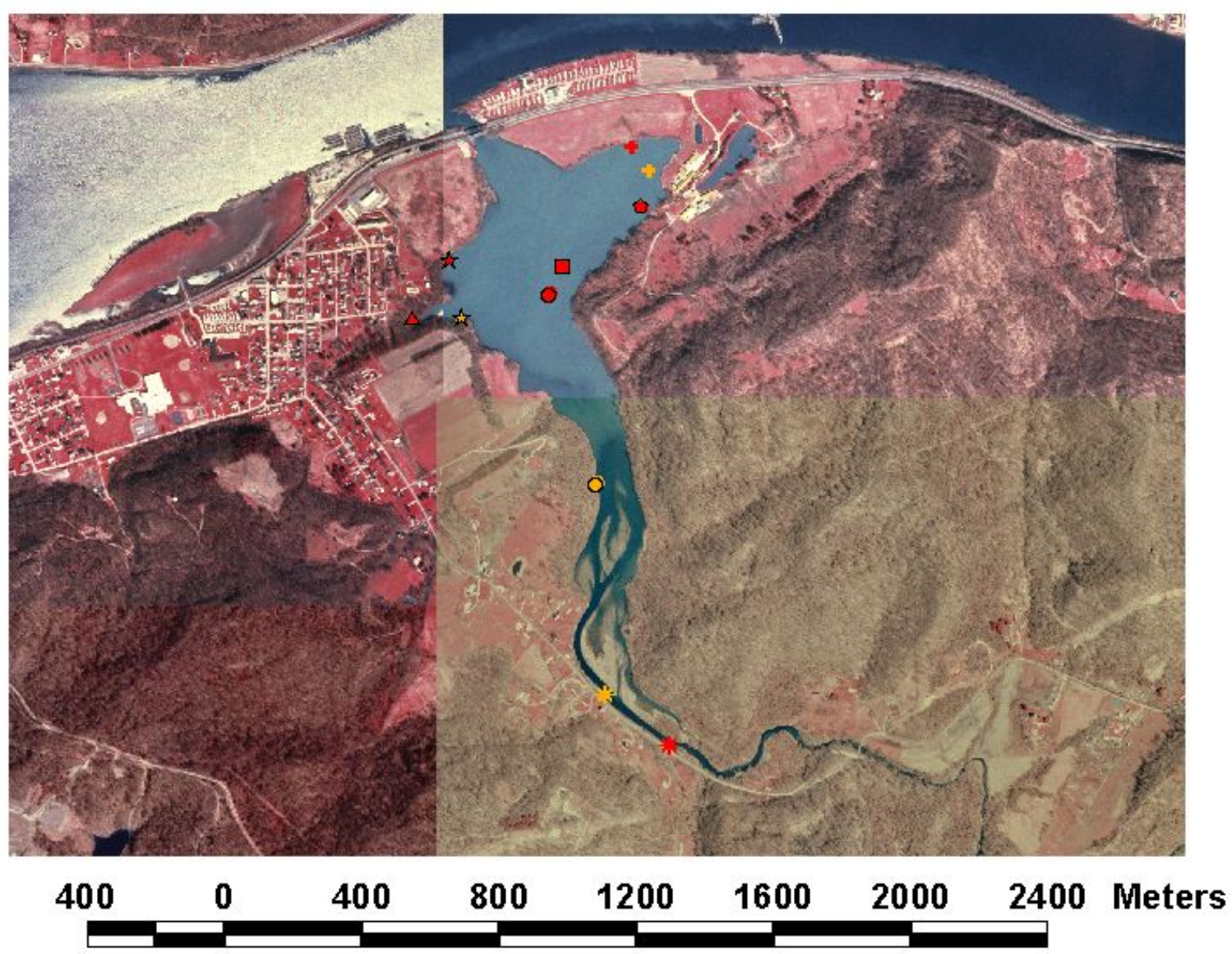

$$
\begin{aligned}
100 & \\
+ & \text { Oct30-1999 } \\
* & \text { Nov06-1999 } \\
181 & \\
* & \text { Nov06-1999 } \\
* & \text { Nov07-1999 } \\
350 & \\
\star & \text { Oct25-1999 } \\
* & \text { Nov06-1999 } \\
581 & \\
* & \text { Aug01-2000 } \\
681 & \\
4 & \text { Aug01-2000 } \\
774 & \\
\square & \text { Mar26-2000 } \\
783 & \\
\bullet & \text { Mar29-2000 } \\
0 & \text { May10-2000 }
\end{aligned}
$$

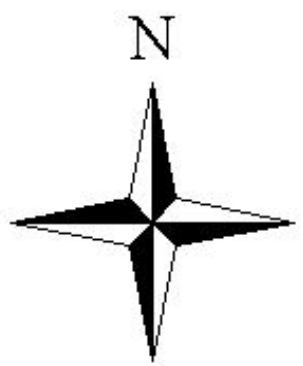

Figure A-4. Radio telemetry locations within the French Run embayment for the subadult largemouth bass tagged with frequencies 48.100, 48.181, 48.350, 48.581, $48.681,48.774$, and $48.783 \mathrm{mHz}$. 

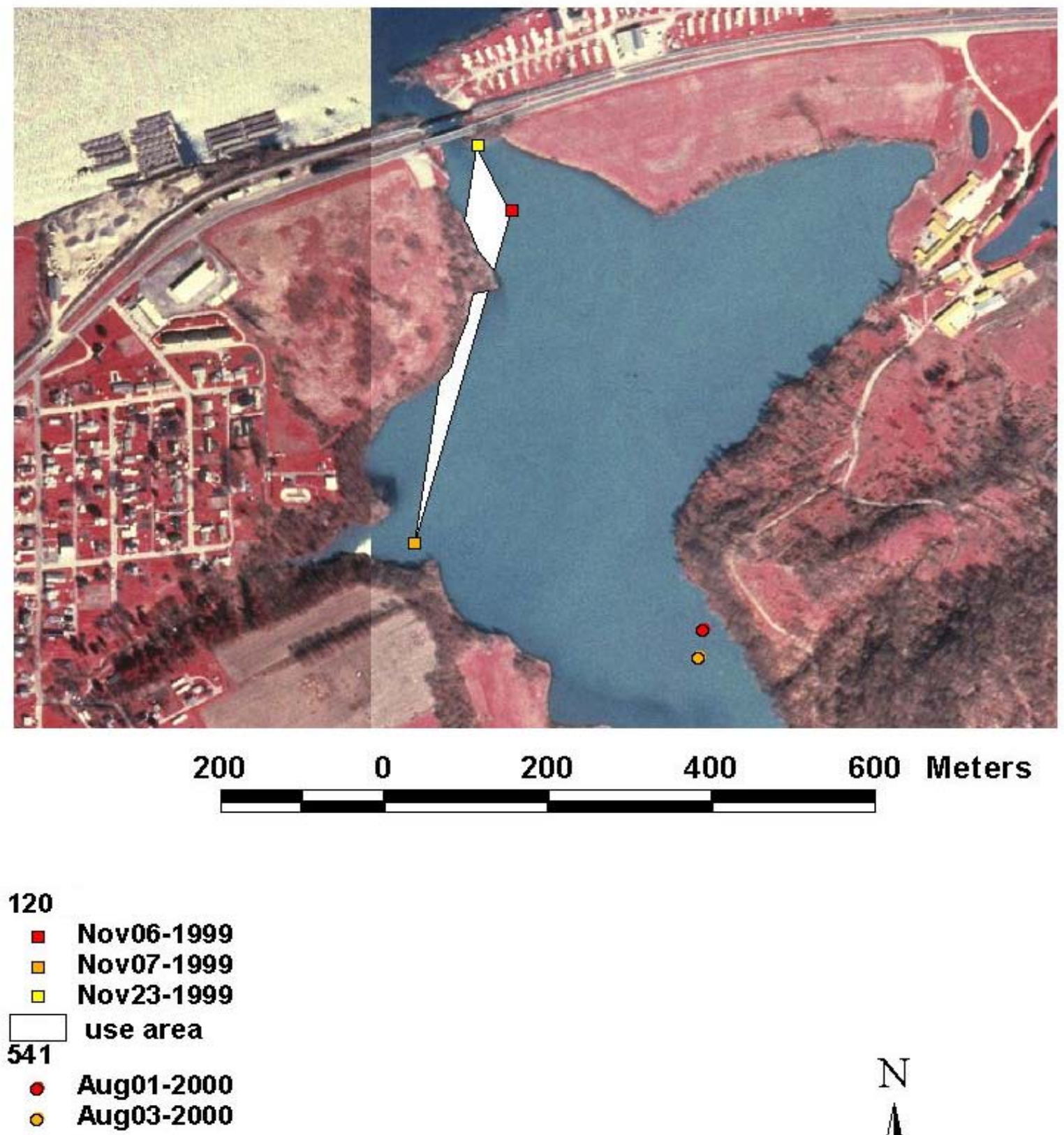

Figure A-5. Radio tlemetry locations and core use area within the French Run embayment for the subadult largemouth bass tagged with frequencies 48.120 and $48.541 \mathrm{mHz}$. 

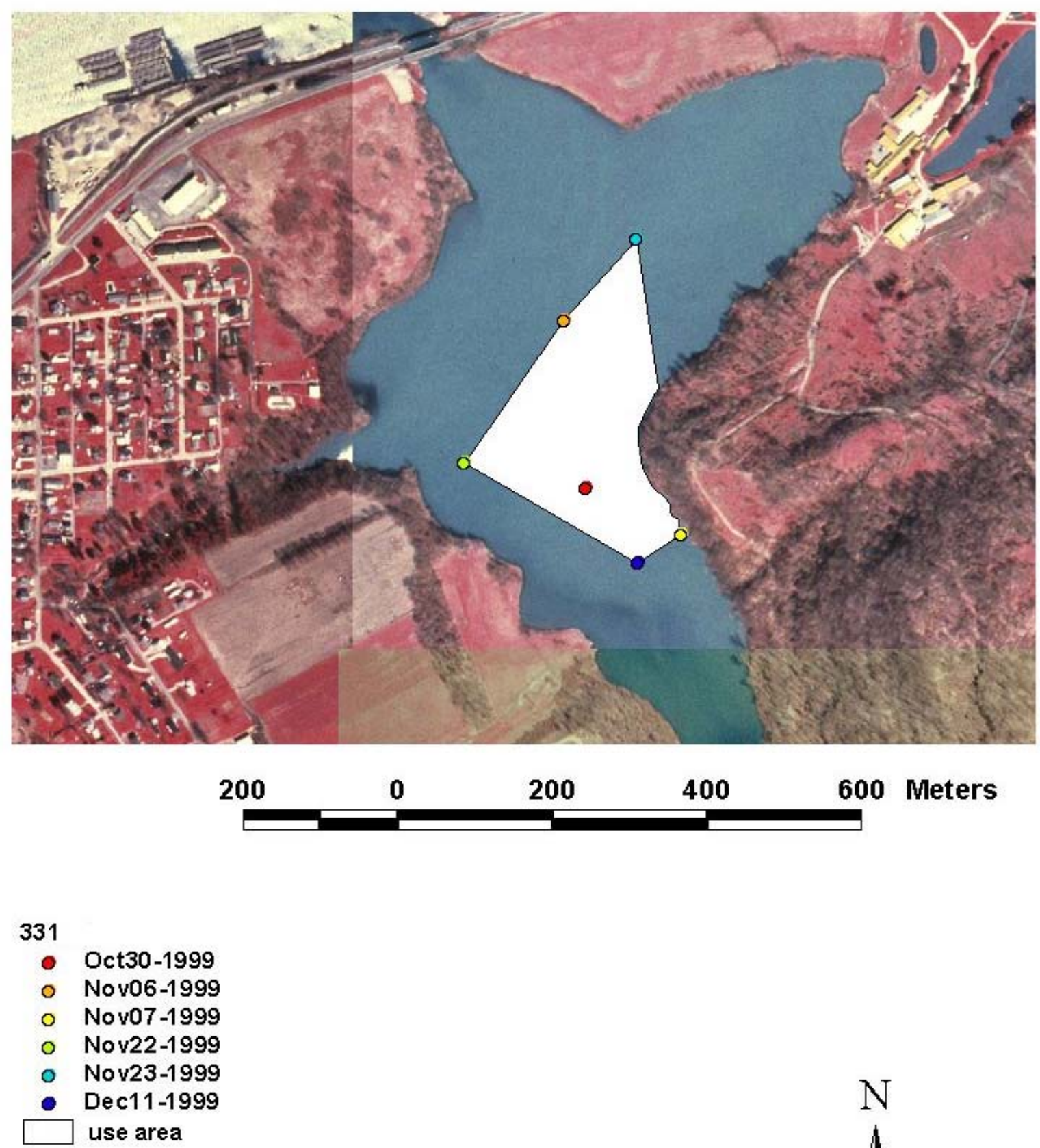

Figure A-6. Radio tlemetry locations and core use area within the French Run embayment for the subadult largemouth bass tagged with frequency $48.331 \mathrm{mHz}$. 


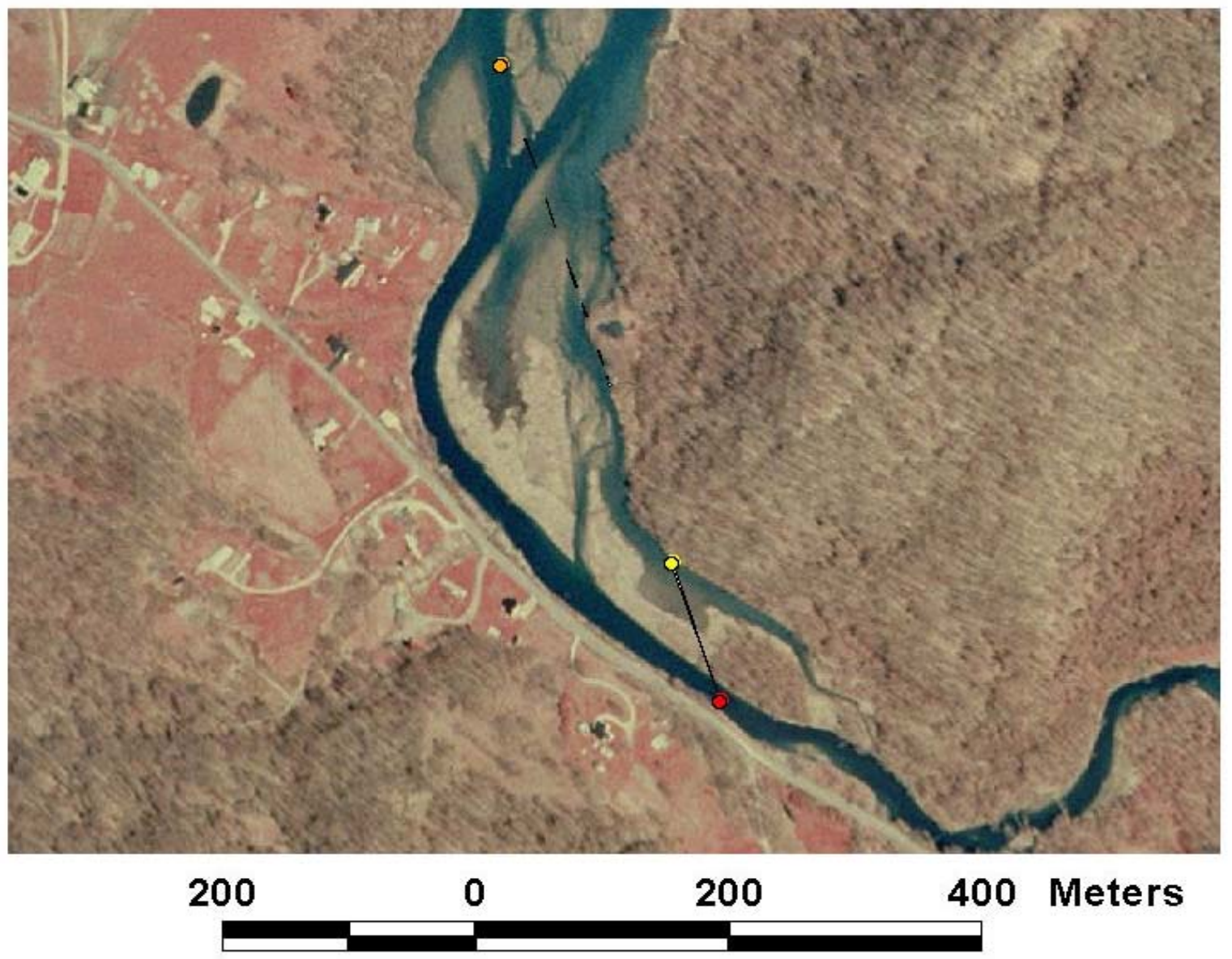

130

- Oct30-1999

- Nov06-1999

- Nov07-1999

use area

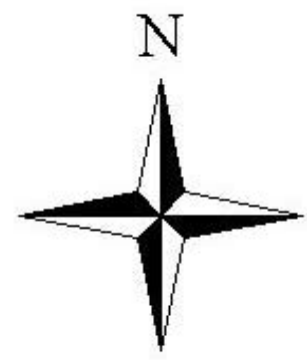

Figure A-7. Radio telemetry locations and core use area within the French Run embayment for the subadult largemouth bass tagged with frequency $48.130 \mathrm{mHz}$. 

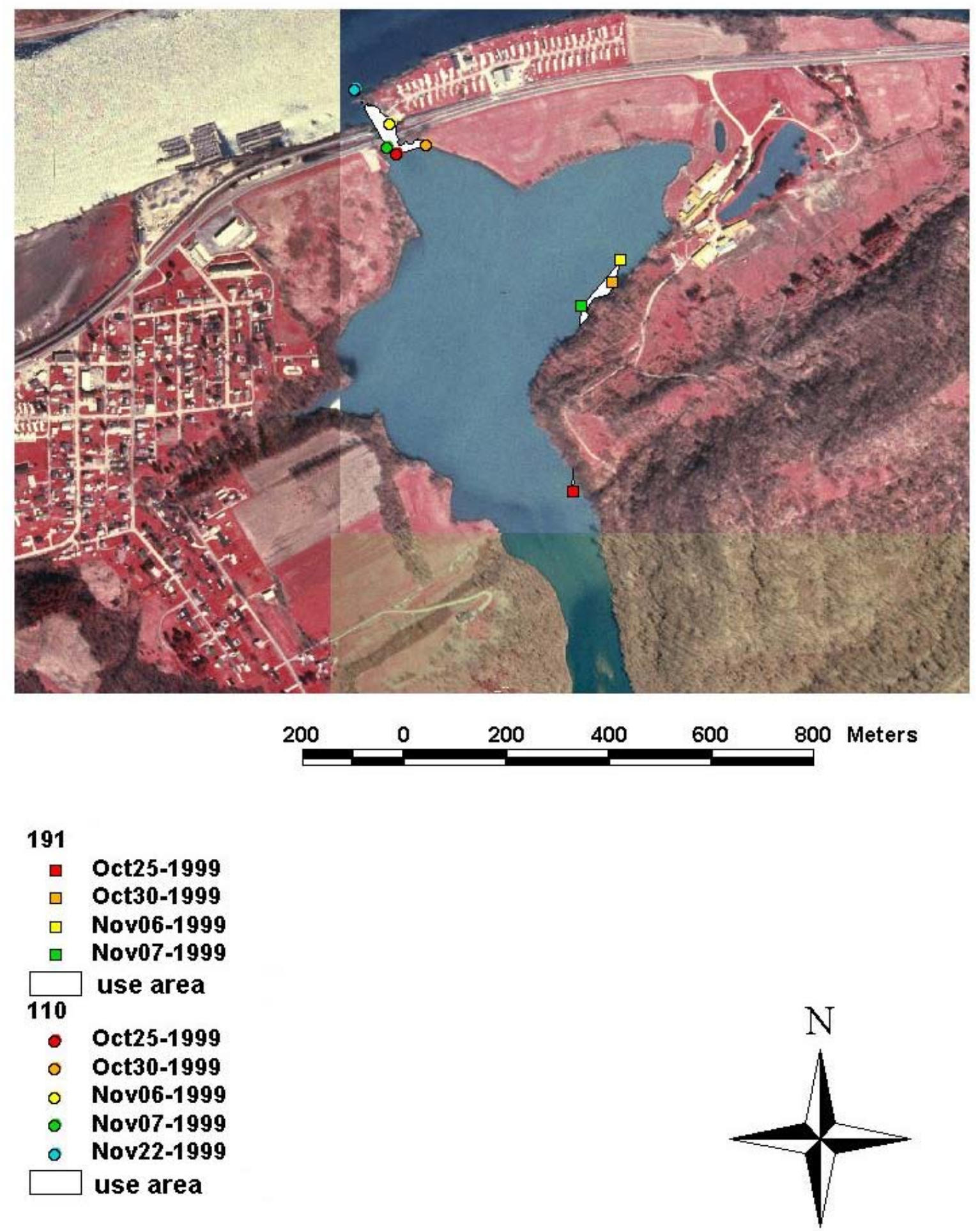

Figure A-8. Radio tlemetry locations and core use areas within the French Run emabyment for the subault largemouth bass tagged with frequencies 48.191 and $48.110 \mathrm{mHz}$. 

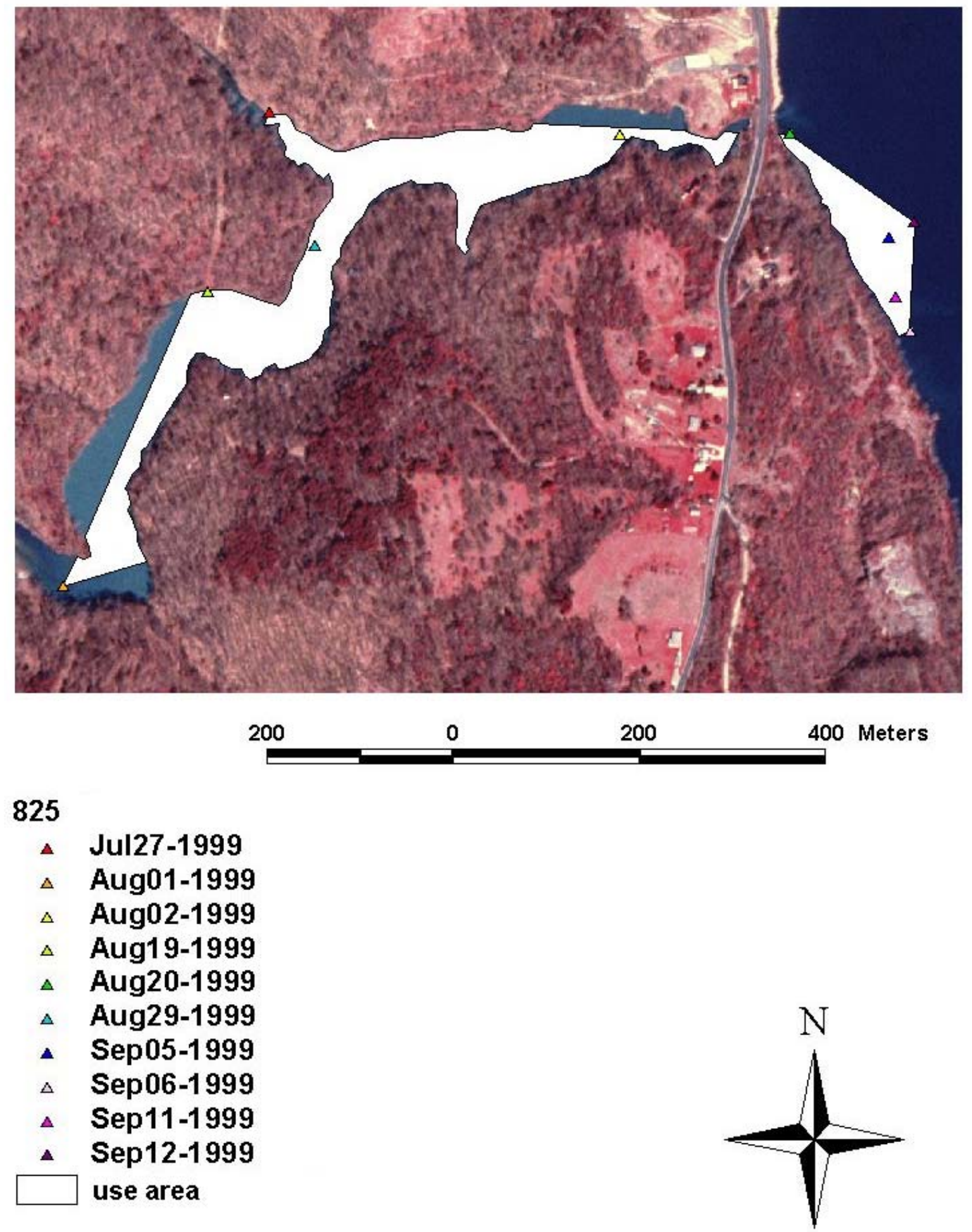

Figure A-9. Radio telemetry locations and core use area within the Indian Run tributary for the subadult largemouth bass tagged with frequency $48.825 \mathrm{mHz}$. 

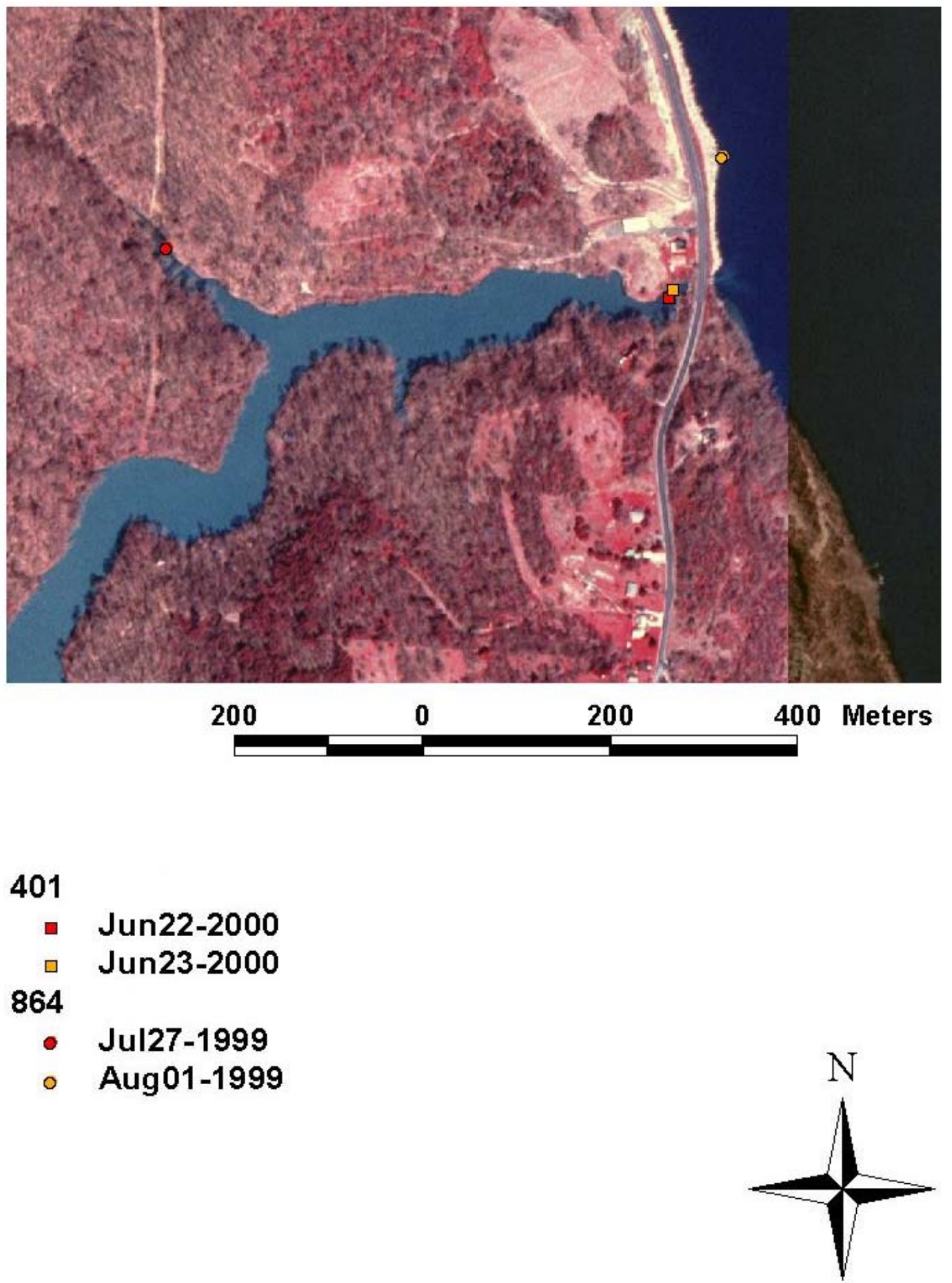

Figure A-10. Radio telemetry locations within the Indian Run tributary for the subadult largemouth bass tagged with frequencies 48.401 and $48.864 \mathrm{mHz}$. 

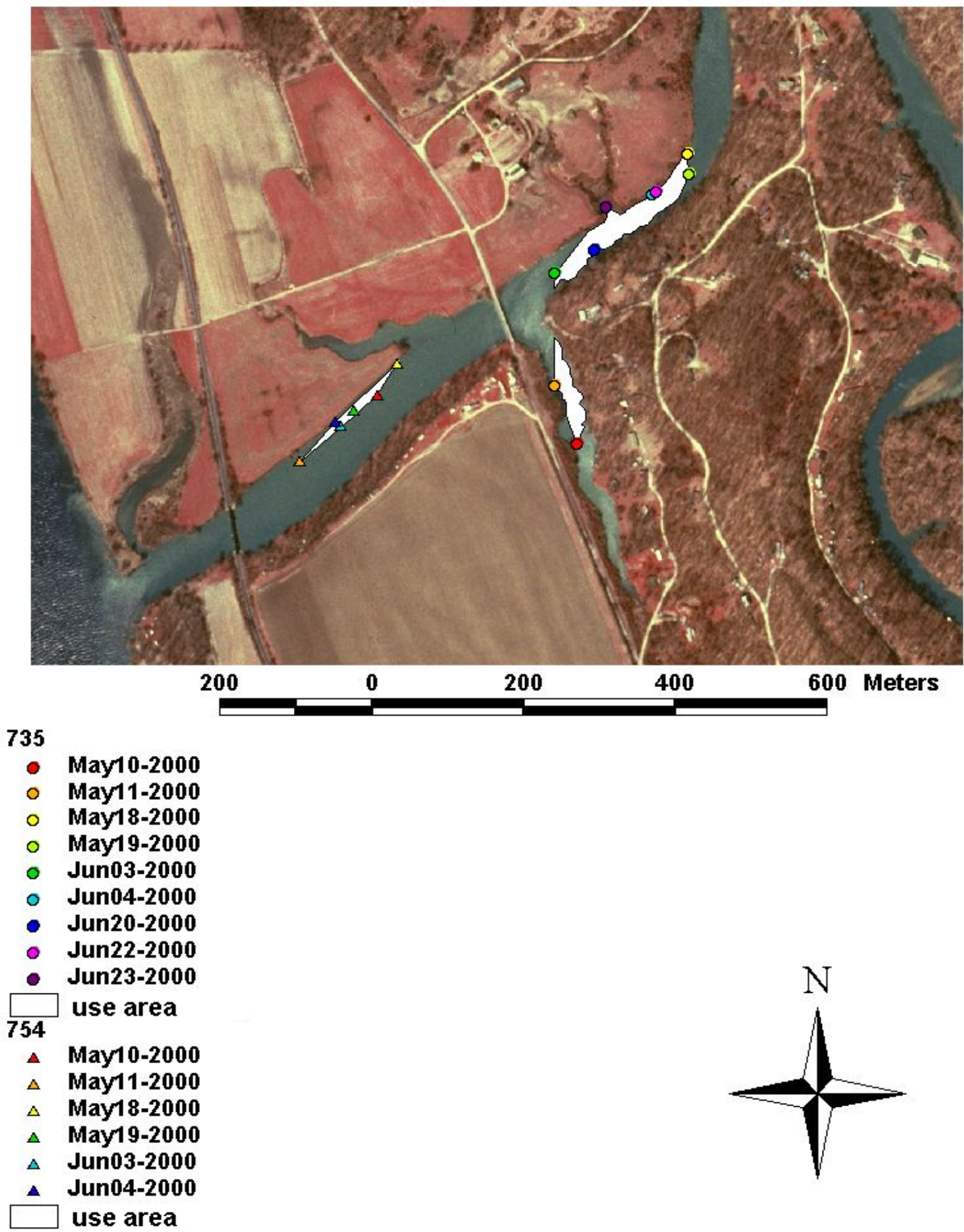

Figure A-11. Radio telemetry locations and core use areas within the Lee Creek tributary for subadult largemouth bass tagged with frequencies 48.735 and $48.754 \mathrm{mHz}$. 

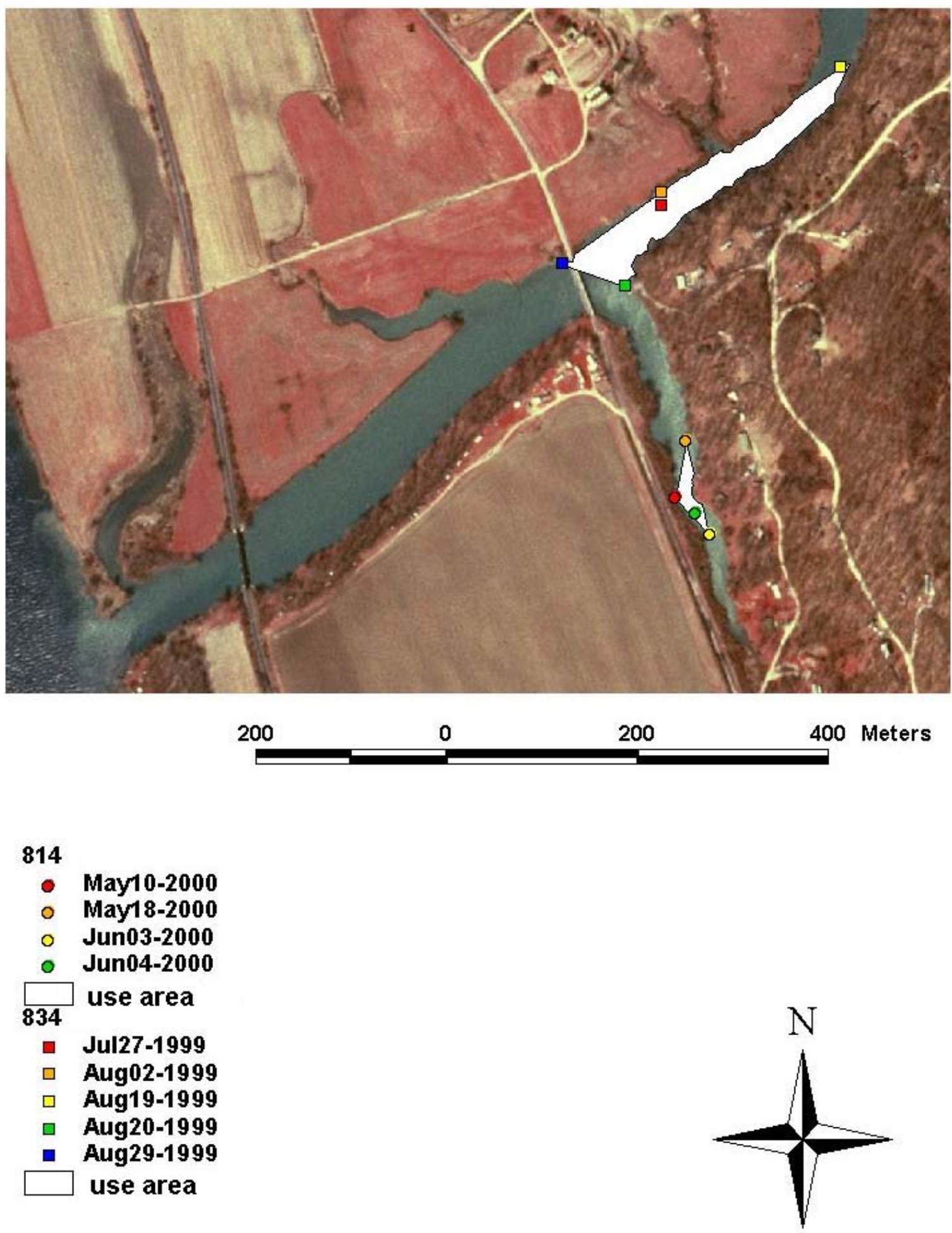

Figure A-12. Radio telemetry locations and core use areas within the Lee Creek tributary for subadult largemouth bass tagged with frequencies 48.814 and $48.834 \mathrm{mHz}$. 

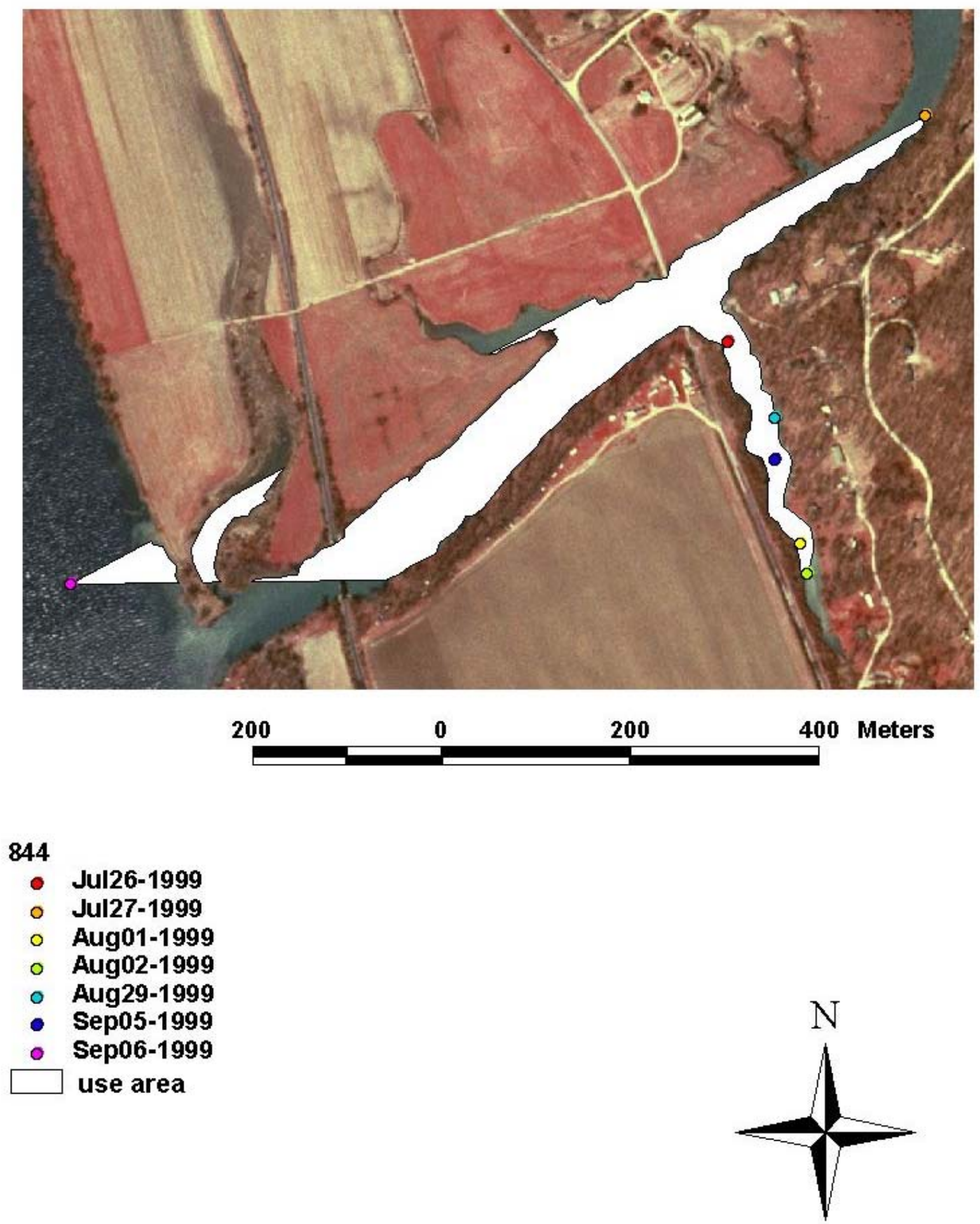

Figure A-13. Radio telemetry locations and core use area within the Lee Creek tributary for the subadult largemouth bass tagged with frequency $48.844 \mathrm{mHz}$. 

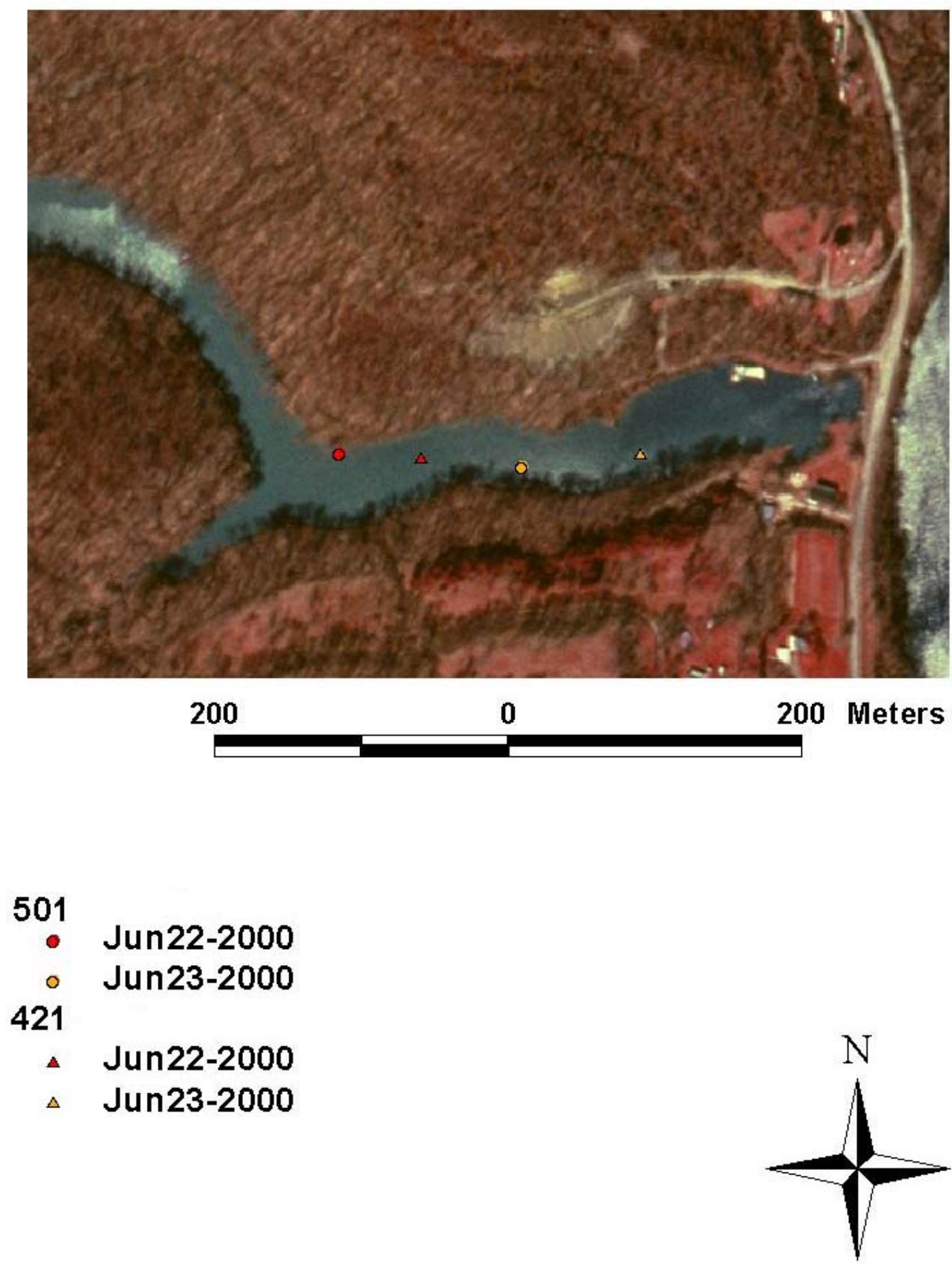

Figure A-14. Radio telemetry locations within the Sugarcamp Run embayment for the subadult largemouth bass tagged with frequencies 48.501 and $48.421 \mathrm{mHz}$. 

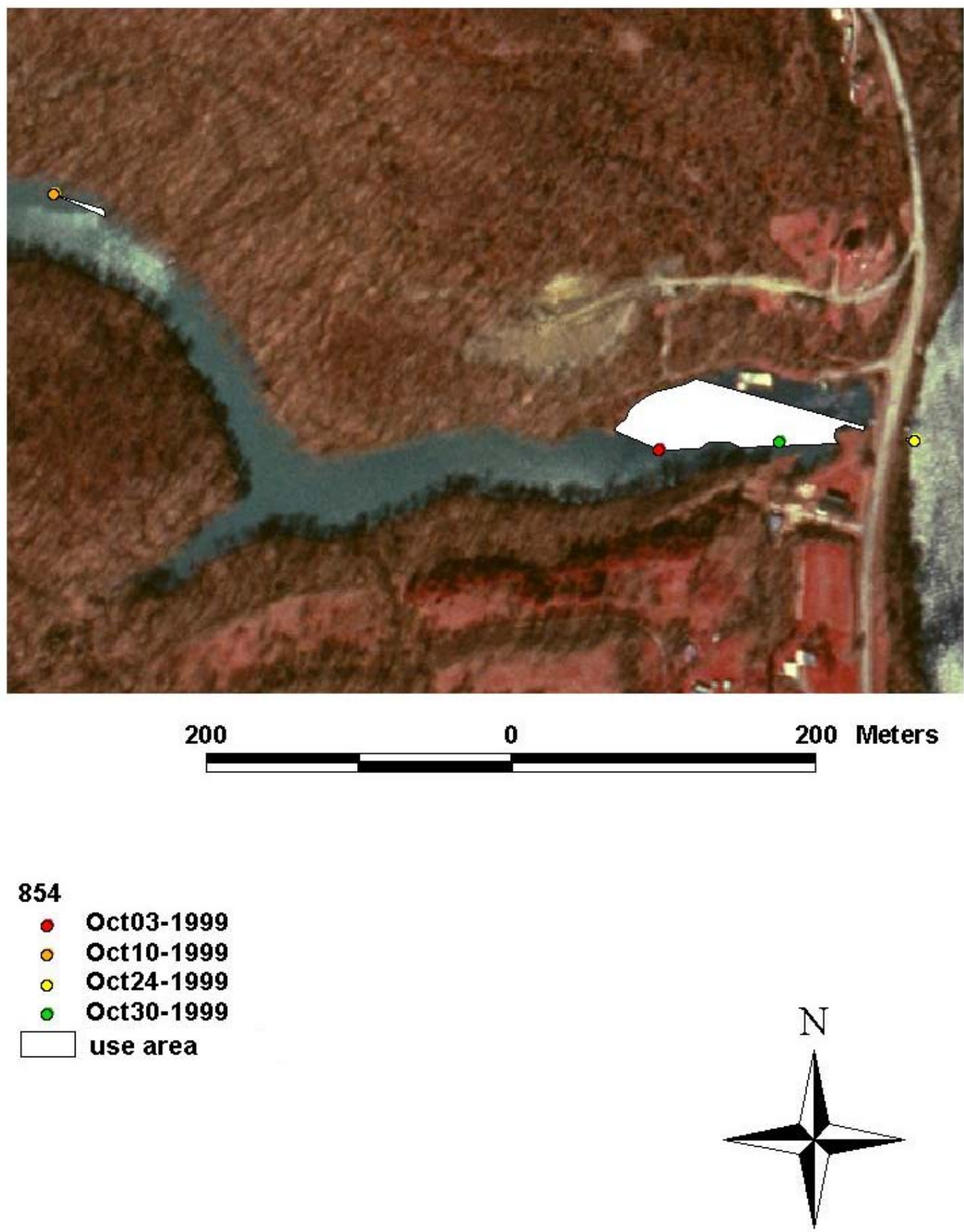

Figure A-15. Radio telemetry locations and core use area within the Sugarcamp Run embayment for the subadult largemouth bass tagged with frequency $48.854 \mathrm{mHz}$. 


\section{Elizabeth Marie Hoffman}

4714 Heath Avenue

Tampa, FL 33624

Phone (813) 960-5696

devilray77@aol.com

\section{EDUCATION}

West Virginia University

July 1998- August 2001

Morgantown, WV

MS Wildlife and Fisheries Resources

Thesis: Habitat utilization and movement patterns of subadult largemouth bass (Micropterus salmoides) in the Ohio River.

Major professor: Kyle J. Hartman

GPA: 3.44

Relevant coursework: Fish Ecology, Fisheries Management, Fish Physiology, Fish and Wildlife Toxicology, Conservation Biology, Ichthyology, Biostatistics, Statistical Methods I \& II.

University of Tampa

Tampa, FL

BS Marine Science

Minor: Chemistry
August 1994- December 1997

Senior seminar: Hydrothermal vents and cold water seeps.

Relevant coursework: Ecology, Invertebrate and Vertebrate Zoology, Environmental Chemistry, Marine Botany, Marine Zoology, Physical Oceanography, Conservation Biology, Genetics, Organic Chemistry I \& II, Physics I \& II. 


\title{
WORK EXPERIENCE
}

\author{
Graduate Teaching Assistant \\ Department of Biology \\ West Virginia University \\ Morgantown, WV \\ August 2000- December 2000 \\ Instructor for 4 weekly biology laboratory classes. \\ Responsible for design of and conducting lectures, quizzes, weekly assignments, and \\ lab reports.
}

Supervisor: Dr. Joseph Marshall

Phone (304)293-5201

Graduate Research Assistant

Division of Forestry

July 1998- August 2000

West Virginia University

Morgantown, WV

Conducted field research pertaining to thesis subject.

Collected fish using a boat electrofishing system.

Field surgical implantation of radio transmitters.

Telemetry surveys using ATS tracking equipment.

Water quality analysis using YSI equipment.

Habitat assessment using randomized transects.

Mapping and analysis of fish locations in GIS environment.

Supervisor: Dr. Kyle J. Hartman

Phone (304)293-2941

Research Assistant

March 1996- August 1997

Department of Biology

University of Tampa

Tampa, FL

Responsible for data collection and entry; aided in analysis.

Gear preparation and maintenance.

Collection of study volunteers.

Presentation of findings at professional society meeting.

Co-author of manuscript concerning short-term mortality of marine sportfish and angler catch rates during catch and release fishing using barbed and barbless hooks.

Supervisor: Dr. Jeff Schaeffer

Phone (734)994-3331 
Internship

June-July 1996

Florida Department of Environmental Protection

Tampa, FL

Introduced to Trimble global positioning systems (GPS) equipment.

Trained on use of ESRI ArcView mapping software.

\section{PRESENTATIONS}

Hoffman, E.M. and K.J. Hartman. 2000. "Juvenile largemouth bass habitat use and movement in the Ohio River." Poster presentation at the American Fisheries Society Annual Meeting. St.Louis, MO.

Hoffman, E.M. and K.J. Hartman. 2000. "Juvenile largemouth bass habitat use and movement in the Ohio River." Oral presentation at the Northeastern Fish \& Wildlife Agencies Conference. Charleston, WV.

Hoffman, E.M. and K.J. Hartman. 2000. "Juvenile largemouth bass habitat use and movement in the Ohio River." Oral presentation at the Tri-state Fisheries Conference. Lexington, VA.

Hoffman, E.M, J.S. Schaeffer, C. Gutman, R. Emerson, and K. Murray. 1997. "An analysis of angler catch rates using barbed and barbless hooks." Poster presentation at the American Fisheries Society Annual Meeting. Monterey, CA.

\section{PUBLICATIONS}

Schaeffer, J. S. and E. M. Hoffman. 2001. "Effects of barbed and barbless hooks on angler catch rates and short-term mortality of marine fishes." North American Journal of Fisheries Management. (In press).

\section{SPECIALIZED SKILLS}

Computer skills: SAS programming, word processing, spreadsheets, database, PowerPoint, ArcView

Compound and dissecting microscopy

Sample preparation and identification

Boat and backpack electrofishing

Radio telemetry

Data collection using trawls, seining, transects, quadrats

Maryland Department of Natural Resources Boating Safety 
US Department of the Interior Federal Motorboat Operators Class

CPR \& First Aid certified

Open water scuba diver (PADI)

\section{VOLUNTEER EXPERIENCE}

Assisted West Virginia Division of Natural Resources during Northeastern Fish \& Wildlife Agencies Conference (2000)

Assisted fellow graduate students with collection of data on the Ohio and Monongahela Rivers and Deckers Creek in West Virginia and the Hudson River in New York (19982000)

Assisted West Virginia Division of Natural Resources in assessing extent of a fish kill on the Ohio River (1999)

\section{PROFESSIONAL MEMBERSHIPS}

American Fisheries Society Graduate Student Association

Wildlife Society

Tri-Beta

COMMUNITY SERVICE

Wildlife Society annual game dinner (1999)

University of Tampa's annual Earth day celebration (1994-1997)

Southeastern Student Environmental Conference in Gainesville, FL (1997)

Florida Coastal Clean Up (1994-1996)

Cockroach Bay Salt Marsh Restoration Project (1996)

Hillsborough River Clean Up (1995)

City of Tampa Mayor's Beautification Project (1995) 


\section{AWARDS}

American Fisheries Society Travel award to attend 2000 annual meeting

Community Service Award as president of Environmental Protection Coalition at The University of Tampa

University of Tampa travel award to attend 1997 American Fisheries Society annual meeting

Leadership award as peer organizational advisor at The University of Tampa

Deans list University of Tampa (1997) 